\title{
过渡金属催化去官能团化反应研究进展
}

\author{
董晓娟 金伟伟* 刘晨江* \\ (新疆大学化学化工学院 乌鲁木齐 830046)
}

\begin{abstract}
摘要 官能团是决定有机化合物化学性质的原子或原子团，在有机合成化学中常常扮演着导向基团的角色. 去官能团 化也就是将一个官能团较多的底物, 通过化学方法使之成为官能团较少的化合物. 去官能团化在解决环境问题、应对 资源短缺问题以及生物质降解等方面有积极的应用. 但由于化学键键能的存在，化学键的断裂需要能量，去官能团化 常常通过加热、加酸或加碱才能实现. 近年来, 去官能团化一直向着更绿色、更可持续的方向进行. 金属催化为去官能 团化提供了一种新的途径. 总结了近年来不同金属介导的去官能团化反应在有机合成中的应用及其催化反应机理. 关键词 过渡金属; 去官能团化; 质子化; 选择性
\end{abstract}

\section{Recent Advances in Transition-Metal Catalyzed Defunctionalization Reaction}

\author{
Dong, Xiaojuan Jin, Weiwei* Liu, Chenjiang* \\ (School of Chemistry and Chemical Engineering, Xinjiang University, Urumqi 830046)
}

\begin{abstract}
Functional groups are atoms or groups that determine the chemical properties of organic compounds. It often plays the role of guiding group in organic synthesis chemistry. Defunctionalization is the chemical transformation of a substrate with more functional groups into a compound with fewer functional groups, which has positive applications in solving environmental problems, resource shortage and biomass degradation. But due to the bond energy, heating, acid or base are often involved in defunctionalization. In recent years, defunctionalization has been moving toward a greener and more sustainable direction. Metal catalysis provides a new way for defunctionalization. The recent applications of different metalmediated defunctionalization in organic synthesis and their mechanism are summarized.
\end{abstract}

Keywords transition metal; defunctionalization; protonation; selectivity

去官能团化即将含多个官能团的化合物脱去某个 官能团而形成含官能团较少的化合物. 去官能团的主要 挑战在于 $\mathrm{C}-\mathrm{X}$ 键 $(\mathrm{X}=\mathrm{C}$ 或其他原子 $)$ 的高键能. 由于键 能的存在, 某个化学键之间的断裂就需要通过酸、碱、 催化剂或加热等手段实现. 而金属通过单个或两个电子 传递过程破坏了 $\mathrm{C}$ - X 键, 使去官能团化反应较容易发 生. 将去官能团化的有机合成反应应用于实际生产生活 是化学家们一直追求的目标 ${ }^{[1]}$. 近年来去官能团化在解 决环境问题、应对资源短缺问题以及生物质降解等方面 有积极的应用. 去官能团化的发展向着绿色、可持续 ${ }^{[2]}$ 的方向进行. 去官能团化在有机合成中有着直接的影 响, 比起官能团化, 去官能团化在多方面体现着自己的 价值(如天然药物的合成、木质素降解 ${ }^{[3]}$ 等). 此外, 去官
能团化在交叉偶联反应 ${ }^{[4]}$ 中有着重要应用.

本文将介绍近 20 年来不同金属介导的不同官能团 脱去反应在有机合成中的应用.

\section{1 钯催化的去官能团化反应}

\section{$1.1 \mathrm{C}-\mathrm{C}$ 键的断裂}

\subsection{1 脱羧}

2004 年, Matsubara 等 ${ }^{[5]}$ 以 $\mathrm{Pd} / \mathrm{C}$ 为催化剂, 水热法实 现了重水环境下游离羒酸的脱羒気化反应. 不同于简单 的加热反应，反应在高压釜中进行，周围的水阻止了有 机化合物的分解，反应的不足之处在于需要 $250{ }^{\circ} \mathrm{C}$ 的 高温反应才能有效进行, 反应机理尚不明确(Eq. 1).

\footnotetext{
* Corresponding authors. E-mail: wwjin0722@163.com; pxylcj@126.com Received February 26, 2020; revised April 10, 2020; published online April 23, 2020.

Project supported by the National Natural Science Foundation of China (Nos. 21702175, 21961037) and the 1000 Youth Talents Plan. 国家自然科学基金(Nos. 21702175, 21961037)和青年千人计划资助项目.
} 


$$
\mathrm{R}-\mathrm{COOH} \underset{\mathrm{D}_{2} \mathrm{O}, 250^{\circ} \mathrm{C}, 5 \mathrm{MPa}}{\stackrel{10 \% \mathrm{Pd} / \mathrm{C}(5 \mathrm{~mol} \%)}{\longrightarrow}} \mathrm{R}-\mathrm{D}
$$

2007 年, Kozlowski 等 ${ }^{[6]}$ 以三氟乙酸为氢源, 实现了 温和条件下钯催化芳香羧酸的脱羧反应(Eq. 2), 该方法 可用于合成联萫骨架的芳香化合物，但其仅适用于大位 阻富电子芳香化合物, 核磁共振氢谱实验表明, 芳基钯 物种的良好稳定性是反应能够有效进行的关键.<smiles>COc1cccc(OC)c1C(=O)O</smiles>

$$
\underset{\mathrm{DMSO} / \mathrm{DMF}, 70^{\circ} \mathrm{C}, 24 \mathrm{~h}}{\mathrm{Pd}\left(\mathrm{O}_{2} \mathrm{CCF}_{3}\right)_{2}(20 \mathrm{~mol} \%)} \stackrel{\mathrm{OMe}}{\mathrm{CF}_{3} \mathrm{CO}_{2} \mathrm{H}(10 \text { equiv. }}
$$

\section{1 .2 脱羟甲基}

脱羟甲基在生物化学上有重要作用, 如在活性 DNA 分子的脱羟甲基反应涉及的 $\mathrm{RCH}_{2} \mathrm{OH}$ 氧化为 $\mathrm{RCHO}$ 和后续脱羰基化 $(\mathrm{RCHO}$ 变为 $\mathrm{RH})$ 反应 ${ }^{[7]}$ 中, 脱羟 甲基至关重要. 2013 年, Maiti 等 ${ }^{[8]}$ 以醋酸钯作催化剂, 环己烷作溶剂, 碳酸钠作碱, 最后以中等偏上的产率得 到了目标产物. 该反应底物范围广, 官能团容忍性高. 此外，该反应还可用于天然产物的脱羟甲基化反应中， 胆固醇类天然产物的脱羟甲基化以 $92 \%$ 的收率得到了 目标产物(Scheme 1).

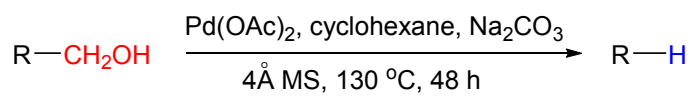

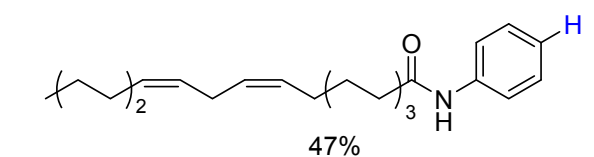

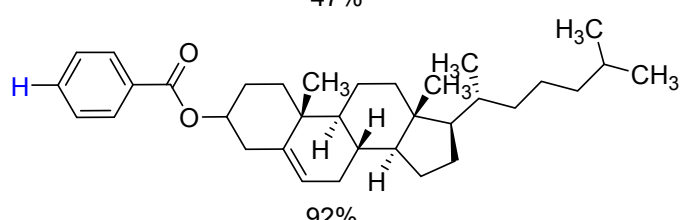

$92 \%$

图式 1 钯催化脱羟甲基在天然产物衍生物合成中的应用 Scheme 1 Application of palladium catalyzed dehydroxymethylation in the synthesis of derivatives of natural products

\subsection{3 脱羰基}

寻找一种高效、通用的脱羰工艺，开发合成可用于 生产燃料级烷烃的方法依旧是市场难题. 2012 年, Maiti 等 ${ }^{[9]}$ 以醋酸钯作催化剂, 环己烷作溶剂, 得到了脱羰基 化反应产物. 同年, 该课题组 ${ }^{[10]}$ 在微波辐射下, 用乙酸 乙酯作溶剂, 以最高 $98 \%$ 的收率得到脱羰基化产物. 并 且该反应还应用到天然产物合成中(Scheme 2).

随着环境问题的日益严重和化石资源的紧缺，人类 对环境污染和资源危机等问题认识不断深入, 为燃料生 产和大宗化学品寻找新的来源势在必行, 因此, 生物质

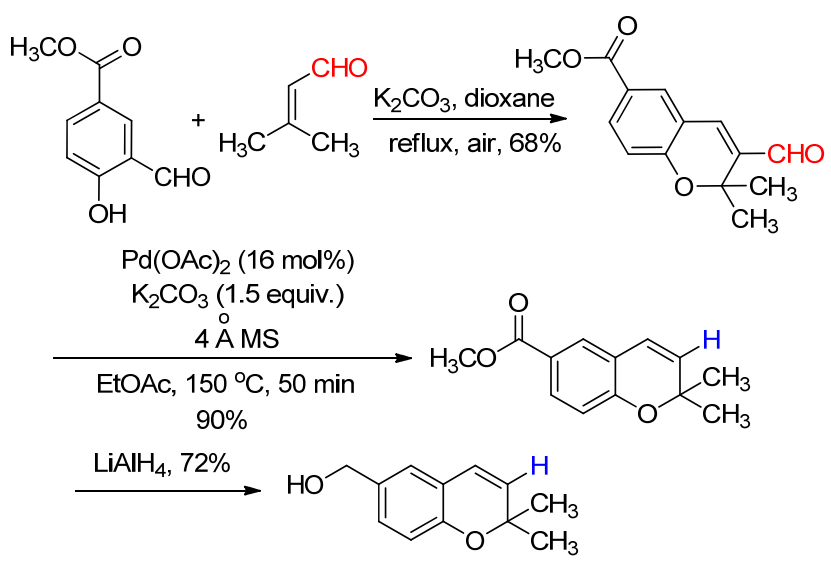

图式 2 钯催化脱羰基的应用

Scheme 2 Application of palladium catalytic decarbonylation 等可再生资源的开发和利用受到人类越来越多的重视. 木质素作为植物重要组成部分, 被视为化石燃料的最佳 替代品. 然而木质素的降解和利用一直以来都充满着挑 战. 众所周知, 来源于生物质的糖比经常使用的化学品 和燃料更富氧. 因此，源自生物质的糖类，通过化学选 择性脱氧生成的产物，是有效的碳水化合物原料中心， 目前主要是通过脱水、脱羰或脱羧实现的. 木质素小分 子 5-羟甲基糠醛的去官能团化多有报道 ${ }^{[11]}$. 2018 年，唐 海涛等 ${ }^{[12]}$ 制备了一种新型钯金属化多孔有机配体 $(\mathrm{Pd}$ NPs/POL-xantphos), 并将其用于醛的化学选择性脱羰 (Eq. 3). 这种非均相催化剂不仅具有优异的催化活性和 化学选择性, 而且在重复使用 10 次后也具有高活性.

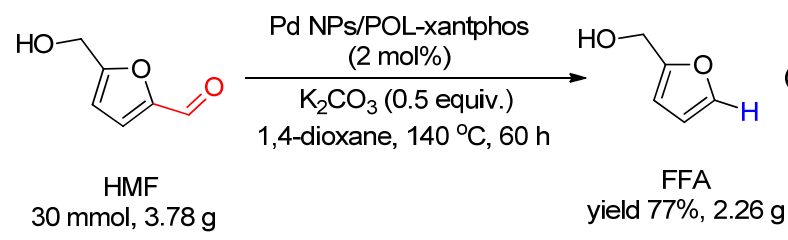

2018 年, Ogiwara 等 ${ }^{[13]}$ 同样以醋酸钯作催化剂, 三 乙基硅烷作氢源，甲苯作溶剂，利用不同配体控制酰基 氟化物不同化学键的断裂(Scheme 3).

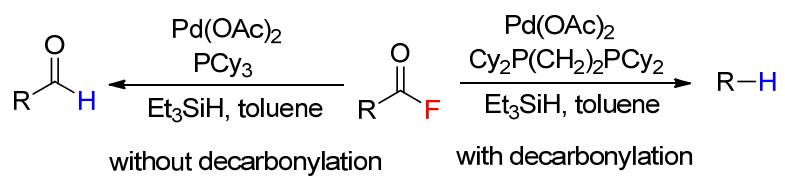

图式 3 钯催化的脱羰基反应

Scheme 3 Palladium catalyzed decarboxylation

\section{$1.2 \mathrm{C}-\mathrm{O}$ 键的断裂}

还原 $\mathrm{C}-\mathrm{O}$ 键 ${ }^{[14]}$ 生成相应的 $\mathrm{C}-\mathrm{H}$ 键是有机化学合 成中最基本的转换之一. $\mathrm{C}-\mathrm{O}$ 键的断裂有着广泛应用, 其中最重要的是在药物分子合成中的应用 ${ }^{[15]}$. $\mathrm{C}-\mathrm{O}$ 键 
的断裂包括碳原子与羟基之间 $\mathrm{C}-\mathrm{O}$ 键断裂及羰基碳原 子和羰基氧原子 $\mathrm{C}-\mathrm{O}$ 键的断裂 ${ }^{[16]}$.

\subsection{1 脱羟基}

虽然苄醚的还原反应是常见的反应，但相应的茮醇 还原反应研究较少. 2013 年, Samec 等 ${ }^{[17]}$ 研究了钯催化 甲酸转移氢解伯茮醇、仲茮醇和叔茮醇, 以高收率得到 目标产物. 其中, 反应中羧酸的加入有助于中间体苯乙 烯的消除(Scheme 4).

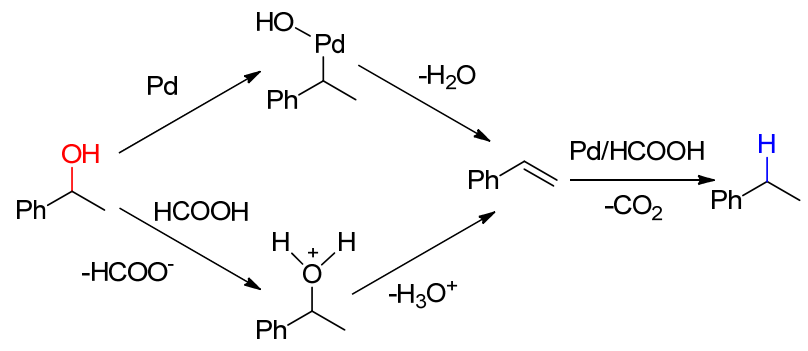

图式 4 钯催化脱羟基反应

Scheme 4 Palladium catalyzed dehydroxylation

\subsection{2 脱磺酰基}

磺酸酯基是易离去基团，被广泛应用于芳基阳离子 的前驱体中 ${ }^{[18]} .2001$ 年, Holmes 课题组 ${ }^{[19]}$ 报道了钯介导 的聚合物负载芳基全氟烷基磺酸盐还原裂解生成芳烃 化合物的反应(Scheme 5).
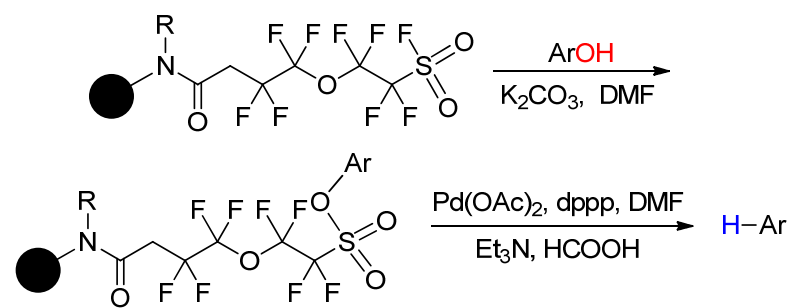

图式 5 钯催化全氟烷基磺酰基的离去

Scheme 5 Palladium catalyzed departures of perfluoroalkyl sulfonyl groups

2006 年, Sajiki 等 ${ }^{[20]}$ 研究了室温下催化量的 $\mathrm{Pd} / \mathrm{C}$ 和 $\mathrm{Mg}$ 共催化脱甲磺酰基的反应. 此反应在室温下进行, 改善了以往反应中化学试剂使用量大及反应温度高等 缺点. 经过进一步研究, 该课题组 ${ }^{[21]}$ 对其机理有了更深 入的了解. 按照可能的机理, 反应过程中加入的 $\mathrm{NH}_{4} \mathrm{OAc}$ 扮演着双重角色, 既加速了 $\mathrm{Mg}$ 盐的溶解, 又 促进了电子的转移, 进而加快了反应速度. 甲醇在反应 中为目标产物提供了质子(Scheme 6).

类罂粟碱类药物(如吗啡碱和可待因)结构复杂, 药 用价值大, 可用作镇痛药, 通过化学方法快速合成此类 天然药物分子具有极重要的意义. 2010 年, Neumeyer 等 ${ }^{[22]}$ 报道了一种醋酸钯催化、三乙基硅烷提供质子的快 速合成吗啡碱衍生物的反应(Eq. 4). 该方法改善了传统

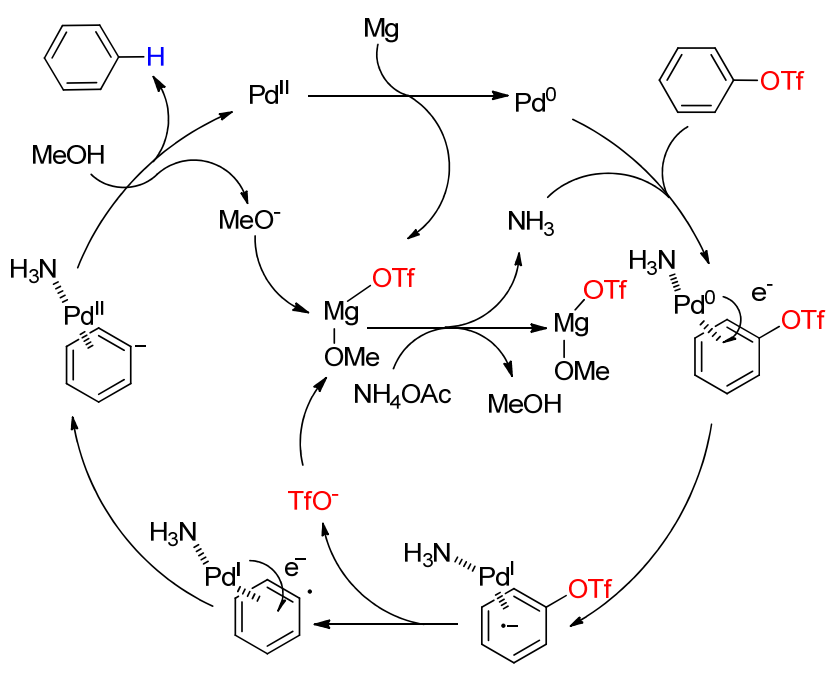

图式 6 钯催化芳基磺酸盐还原脱氧反应可能的反应机理 Scheme 6 Proposed mechanism for palladium catalyzed reductive deoxygention of aryl sulfonate

合成方法的步骤繁琐及产率低等缺点.

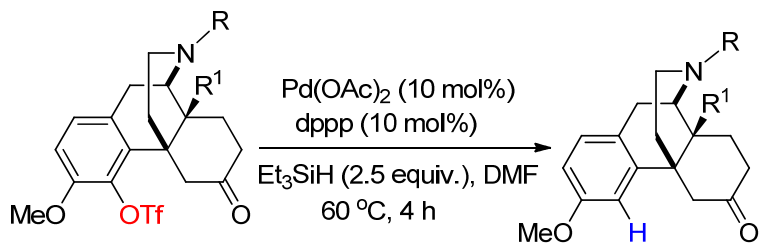

2014 年, Kwong 等 ${ }^{[23]}$ 报道了以醋酸钯作催化剂, 异 丙醇作氢源，芳香族化合物的脱磺酰基反应，反应高效， 且底物范围广。重氢标记实验证明了该反应质子由异丙 醇提供(Eq. 5).

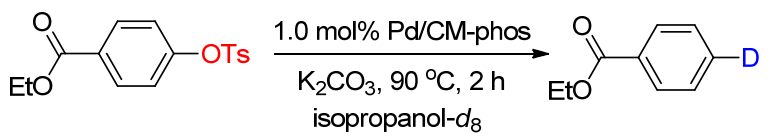

\subsection{C - X 键的断裂}

钯催化的 $\mathrm{C}-\mathrm{X}$ 键的断裂包括碳原子与硫原子、氮 原子和卤素原子之间键的断裂. 2011 年, Graham 等 ${ }^{[24]}$ 报 道了一种温和的且化学选择性和产率高的杂环硫醚切 断反应. 该反应以 $\mathrm{Pd} / \mathrm{C}$ 作催化剂, 四氢呋喃作溶剂, 高 产率地得到了目标产物(Eq. 6), 最高产率可达 99\%. 2012 年, Nakada 等 ${ }^{[25]}$ 以催化量的 $\mathrm{PdCl}_{2}$ 作催化剂, 三乙 基硅烷作氢源，室温下脱甲硫基得到目标产物。该反应 对带有各种官能团的底物都有较好的适应性，但不同底 物在反应时间上有较大的差异. 2014 年, 该课题组 ${ }^{[26]}$ 介 绍了一种用硫脲制备咪唑啉盐的钯催化方法，该方法具 有很大的潜力, 所有的必需试剂都是可商业购买的, 硫 脲在温和的反应条件下，可以安全地转换成相应 NHCs 的前体, 且由该方法生成的 NHCs 的前体较为稳定. 
<smiles>CCOC(=O)c1cncc(N)c1C(=O)OCC</smiles>

2012 年, Sajiki 等 ${ }^{[27]}$ 以 $\mathrm{Pd} / \mathrm{C}$ 作催化剂, 甲醇作溶剂 并提供质子, 在联苯上脱去多个氯原子, 该反应在温和 条件、氮气保护下发生, 并被成功用于多氯联苯的降解. 但是该反应需要化学计量金属镁. 同年, Chelucci 课题 组 ${ }^{[28]}$ 以 $\mathrm{NaBH}_{4}$ 和 $N, N, N^{\prime}, N^{\prime}$-四甲基乙二胺(TMEDA)为氢 源, 使用不同钯作催化剂, 四氢呋喃作溶剂, 室温下得 到脱卤化产物. 该反应底物范围广, 能在各种不同官能 团存在下得到相应脱卤化产物, 化学选择性高.

钯催化的 $\mathrm{C}-\mathrm{N}$ 的断裂鲜有报道. 2018 年, Nakao 等 ${ }^{[29]}$ 报道了以异丙醇作氢源、乙酰丙酮钯作催化剂的反 应，该反应对于带有不同官能团的化合物都有较好的适 应性，在该条件下，不同的硝基芳香化合物都以良好到 优秀的产率得到目标化合物(Eq. 7). 2018 年, Loh 等 ${ }^{[30]}$ 报道了一种钯、镍协同催化天然及非天然氨基酸衍生物 的脱氨基反应, 在该体系下可方便地获得 $\alpha, \beta$-不饱和羰 基化合物.

$$
\begin{aligned}
& \mathrm{Pd}(\mathrm{acac})_{2}(5.5 \mathrm{~mol} \%) \\
& \text { BrettPhos (10 mol\%) } \\
& \mathrm{Ar}-\mathrm{NO}_{2}+\stackrel{\mathrm{HO}}{\mathrm{H}} \underset{\text { dioxane, } 130^{\circ} \mathrm{C}}{\stackrel{\mathrm{K}_{3} \mathrm{PO}_{4}(1.5 \mathrm{mmo})}{\longrightarrow}} \mathrm{Ar}-\mathrm{H}
\end{aligned}
$$

\section{2 镍催化的去官能团化反应}

\section{$2.1 \mathrm{C}-\mathrm{C}$ 键的断裂}

\section{1 .1 脱氧基}

预官能团化在合成化学中有广泛的应用，氰基因其 具有邻位定位效应而备受关注. 2013 年, Maiti 等 ${ }^{[31]}$ 研究 了以 $\mathrm{Ni}(\mathrm{acac})_{2}$ 作催化剂, $\left(\mathrm{Me}_{2} \mathrm{SiH}\right)_{2} \mathrm{O}$ 作氢源, 芳香族及 脂肪族氰基化合物的脱氰反应(Scheme 7). 同年, Maiti 等 ${ }^{[32]}$ 也报道了以镍作催化剂、氢气为氢源的碳一氰键断 裂反应研究，该方法能成功用于大分子化合物的合成.

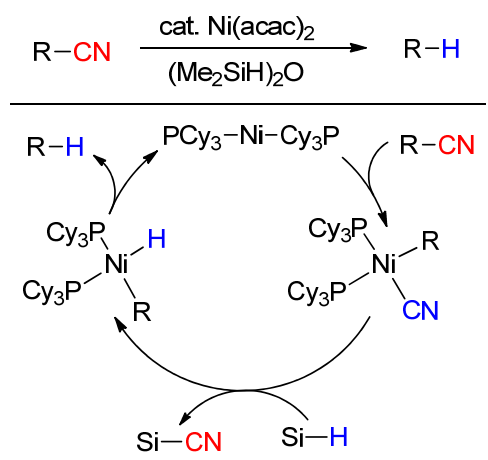

图式 $7 \mathrm{Ni}(\mathrm{acac})_{2}$ 催化脱氰基反应可能的机理 Scheme 7 Proposed mechanism of $\mathrm{Ni}(\mathrm{acac})_{2}$ catalyzed decyanation
该年底, Enthaler 等 ${ }^{[33]}$ 探究了以四氢铝锂作氢源, 镍作预催化剂的脱氰反应，在温和条件下得到 $\mathrm{C}-\mathrm{CN}$ 键断裂的产物.

\subsection{2 脱羰基}

羰基键的断裂包括脱羧反应 ${ }^{[34]}$ 、分子内脱去一分子 $\mathrm{CO}^{[35]}$ 以及脱去游离羰基 ${ }^{[36]} .2017$ 年, 王智谦等 ${ }^{[37]}$ 以催 化量的 $\mathrm{NiCl}_{2}$ 作催化剂, 成功地将分子内脱羰基化反应 应用于含磷化合物的合成中(Scheme 8).

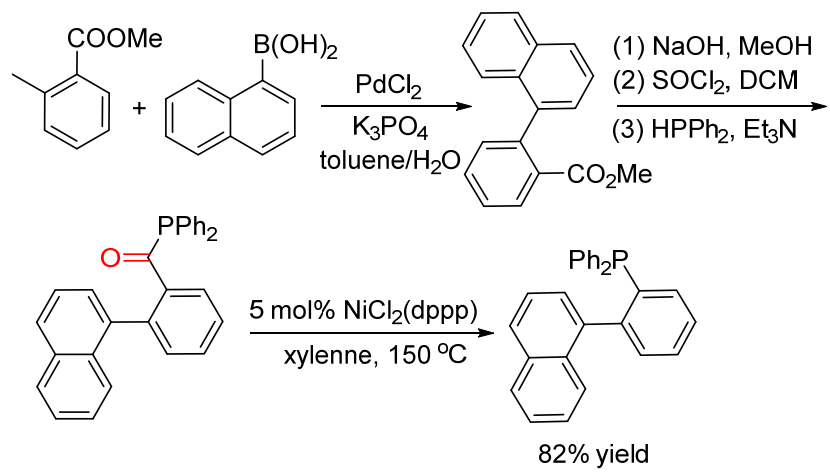

图式 8 镍催化脱羰基的应用

Scheme 8 Application of nickel catalyzed decarbonylation

近年来, Rueping 等 ${ }^{[38]}$ 开发了以廉价金属镍作催化 剂的脱羰基化反应. 该反应还应用于酰胺衍生物中 ${ }^{[39]}$, 在可能的反应机理中 (Scheme 9), $\mathrm{Ni}(\operatorname{cod})_{2}$ 与 $\mathrm{EtPPh}_{2}$ 经过 配体交换形成中间体 1. 接下来, $\mathrm{Ni}(0)$ 与 $\mathrm{CO}-\mathrm{N}$ 键发生 氧化加成形成 $\mathrm{C}-\mathrm{N}$ 键活化的中间体 2. 随后, $\mathrm{CO}$ 迁移 形成中间体 3. 接下来经过氢转移反应形成 $\mathrm{Ni}-\mathrm{H}$ 中间 体 4, 最后还原消除得到目标产物和 $\mathrm{Ni}(0)$ 物种 $\mathbf{5 ,}, \mathbf{5}$ 与原

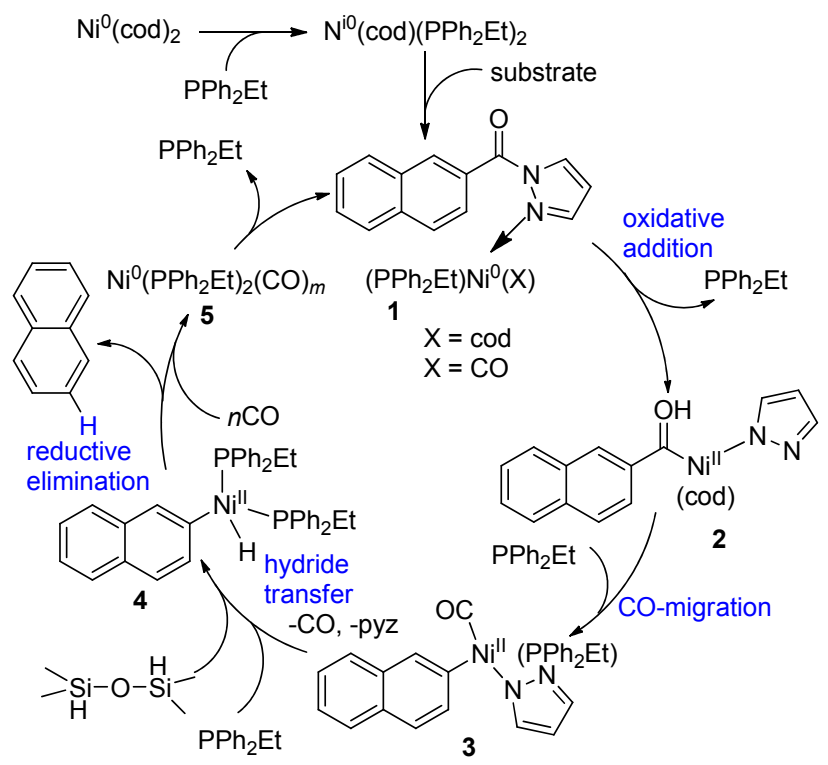

图式 9 镍催化脱羰基反应可能的机理

Scheme 9 Proposed mechanism of nickel catalyzed decarbonylation 
位生成的 $\mathrm{CO}$ 反应继续新的催化循环.

2018 年, 许鹏飞等 ${ }^{[40]}$ 以催化量的镍配合物作催化 剂, 对分子内脱羰基反应做了进一步研究(Eq. 8), 该方 法不仅为丰富 2-取代吲哚类底物的合成提供一种途径, 而且为 $\mathrm{Ni}$ 催化体系设计全新的反应奠定了基础.

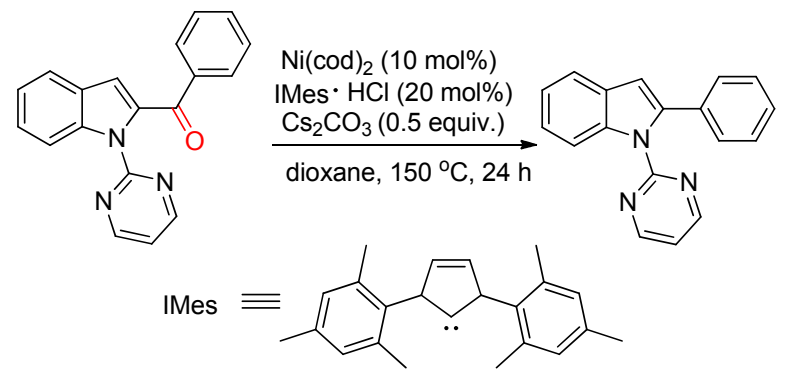

\section{$2.2 \mathrm{C}-\mathrm{O}$ 键的断裂}

由于 $\mathrm{C}-\mathrm{O}$ 键具有较高的能量, 所以其断裂通常需 要苛刻的条件 ${ }^{[41]}$. 近十年来, 醚键的异裂是去官能团化 的研究热点. 2006 年 Lipshutz 等 ${ }^{[42]}$ 以 $N i / C_{g}$ 作催化剂实 现了脱磺酰基反应. $\mathrm{Ni}(\operatorname{cod})_{2}$ 催化的脱甲氧基反应分别 在 2010 年 ${ }^{[43]}$ 和 2011 年 ${ }^{[44]}$ 被陆续报道. 2013 年, Martin 等 ${ }^{[45]}$ 在 $\mathrm{Ni}(\mathrm{cod})_{2}$ 催化下, 以甲苯作溶剂, 高温条件下得 到了 $\mathrm{C}\left(\mathrm{sp}^{2}\right)$ - $\mathrm{OR}$ 键断裂产物(Eq. 9). 2015 年, Tobisu 等 ${ }^{[46]}$ 以镍的配合物作催化剂、叔丁醇钠作碱, 得到了脱甲 氧基的产物(Scheme 10), 最高产率可达 97\%. 该催化体 系以分子内甲基中的氢原子作为氢源, 没有使用额外的 还原剂, 提供了一个原子经济性的过程, 而且该反应还 具有良好的底物适应性.
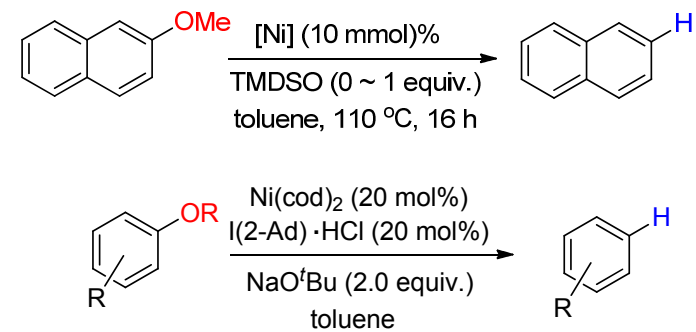

$$
160^{\circ} \mathrm{C}, 18 \mathrm{~h}
$$<smiles>CCOC(C)(C)c1ccc(-c2ccc([SeH])cc2)cc1</smiles>

图式 10 镍催化醚键的断裂

Scheme 10 Nickel catalyzed ether bond fracture

2011 年 ${ }^{[47]}$ 和 2012 年 ${ }^{[48]}$, Hartwig 等实现了 $\mathrm{Ni}(\mathrm{COD})_{2}$ 催化下芳基醚的氢解反应经碳氧键断裂形成芳烃类化 合物. 2018 年, 王中夏等 ${ }^{[49]}$ 通过镍催化, 在异丙醇钠的 作用下实现了芳基或芳基吡啶基醚 $\mathrm{C}-\mathrm{O}$ 键的断裂，并 在相对温和的条件下得到了中等偏上的产率(Scheme 11).

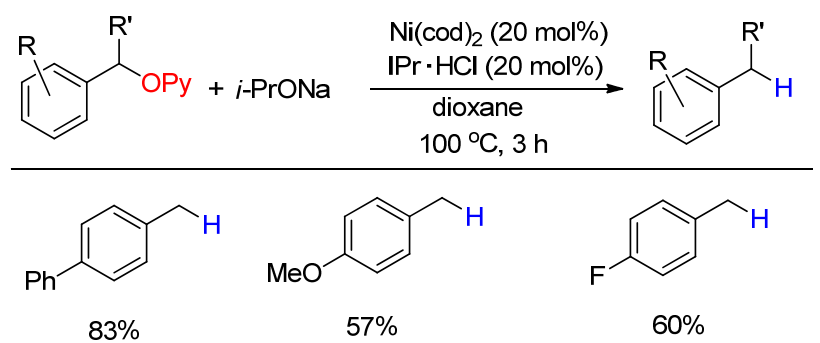

图式 11 镍催化的吡啶基醚键的断裂

Scheme 11 Fracture of pyridine ether bonds catalyzed by nickel

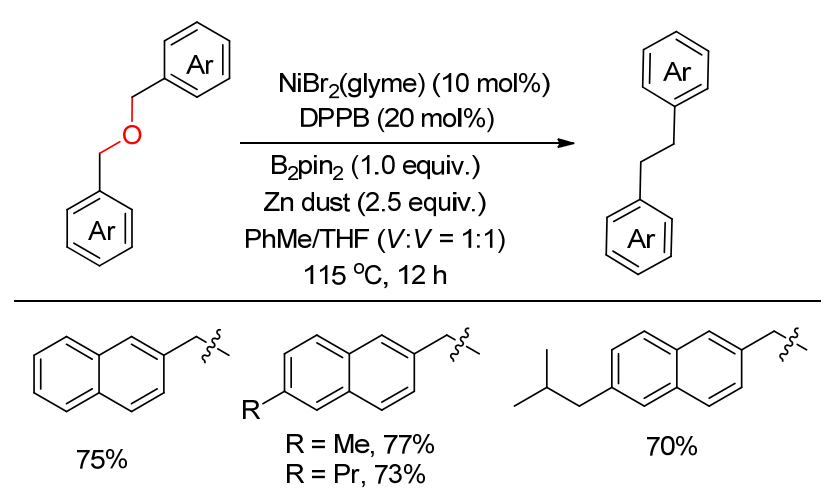

图式 12 镍催化醚类化合物的还原脱氧反应

Scheme 12 Nickel catalyzed reductive deoxygenation of ether compounds

醚类化合物因为具有毒性低和常温下稳定等优点， 在交叉偶联中有较多的应用[如构建 $\mathrm{C}\left(\mathrm{sp}^{3}\right)-\mathrm{C}\left(\mathrm{sp}^{3}\right)$ 键]. 2017 年, 施章杰等 ${ }^{[50]}$ 提出了一种在镍催化下苄基醚分 子内脱去一个氧原子的反应, 通过活化两边的 $\mathrm{C}-\mathrm{O}$ 键, 实现了饱和碳原子之间 $\mathrm{C}-\mathrm{C}$ 键的构建(Scheme 12).

\section{$2.3 \mathrm{C}$ - $\mathrm{X}$ 键的断裂}

镍催化的 $\mathrm{C}-\mathrm{X}$ 键的断裂包括 $\mathrm{C}-\mathrm{Cl}$ 键、 $\mathrm{C}-\mathrm{S}$ 键 以及 $\mathrm{C}-\mathrm{N}$ 键. 2001 年 Lipshutz 等 ${ }^{[51]}$ 用 $\mathrm{Ni} / \mathrm{C}$ 作催化剂, 回流得到还原的芳香烃化合物. 联苯类化合物及苯丙氨 酸甲酯在该体系中均高收率地生成了脱氯产物(Eq. 10). 但该反应底物范围不够广, 且底物中含有不同官能团 时, 要得到脱氯化产物需耗费额外时长才能完成.

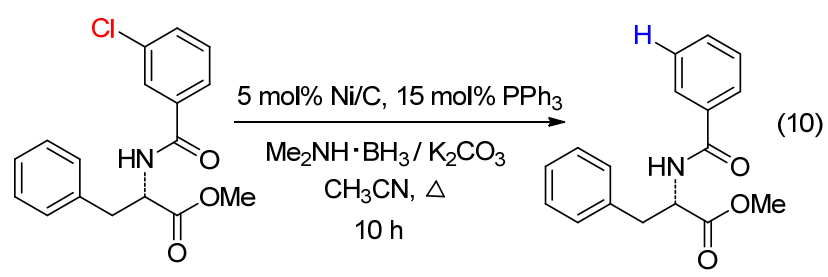

硫原子与金属原子有很好的亲和性，故而限制了金 属催化剂在含硫化合物去官能团化反应中的应用. 2012 年, Martin 等 ${ }^{[52]}$ 利用镍催化，用二甲基乙基硅烷作氢源， 以中等偏上的产率得到了脱甲硫基化产物(Scheme 13), 该反应具有底物范围广、化学选择性高及反应条件温和 
等优点.

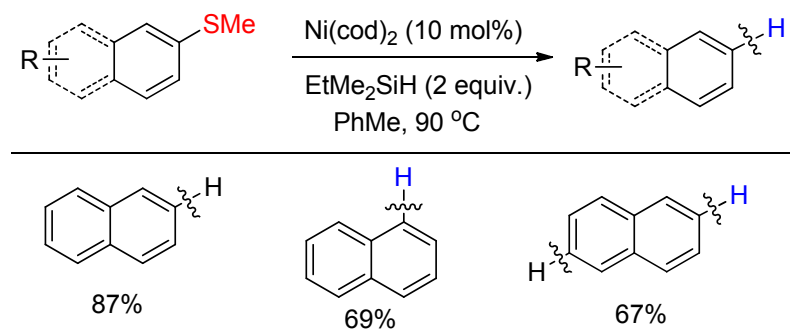

图式 13 铑催化䒺甲基硫醚的还原脱硫反应

Scheme 13 Rhodium catalyzed reductive desulfurization of naphthalene methyl thioether

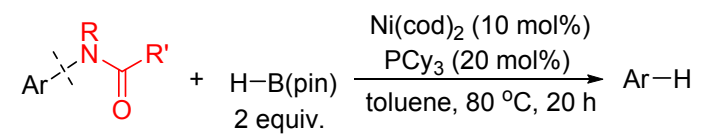<smiles>C[N+]([O-])([O-])c1ccc2ccc(-c3ccccc3)cc2c1</smiles>

$72 \%$

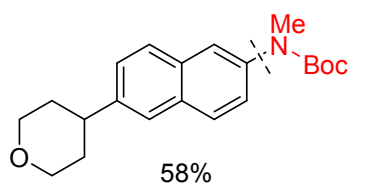

$58 \%$
图式 14 镍催化的 $\mathrm{C}-\mathrm{N}$ 键的断裂

Scheme 14 Nickel catalyzed cleavage of carbon-nitrogen bonds

传统上, 苯胺衍生物(芳基) $\mathrm{C}-\mathrm{N}$ 键的裂解是通过 反应活性高的阳离子中间体如重氮盐和季铵盐来完成 的. 2014 年, Tobisu 等 ${ }^{[53]}$ 以频哪醇氢嗍烷试剂作氢源, $\mathrm{Ni}(\operatorname{cod})_{2}$ 作催化剂, 反应分别生成相应的还原或嗍化产 物(Scheme 14). 但该反应的反应机理以及反应底物范 围还有待进一步研究.

\section{3 铑催化的去官能团化反应}

铑催化的去官能团化反应包括碳原子与羰基键的 断裂、碳原子与氰基键的断裂以及碳原子与硫原子之间 的断裂.

\subsection{C - C 键的断裂}

2006 年, Madsen 等 ${ }^{[54]}$ 对芳香族羰基化合物脱羰基 化反应进行了探究. 2008 年, 该课题组 ${ }^{[5]}$ 提出了芳香族 羰基化合物脱羰基化反应的可能机理. 在提出的可能的 反应机理中, 脱羰基化反应始于磷酸基与平面正方形铑 配体 6 的分离, 而后生成一个不饱和 $\mathrm{d}^{8}$ 复合体 8 . 不饱 和的物种随后在 $\mathrm{C}(\mathrm{O})-\mathrm{H}$ 键中发生快速、可逆的氧化加 成反应, 形成一个酰基铑氢化物 9. CO 迁移产生 18 电子 的烷基或芳基铑氢化物 10, 最后产生 16 电子的复杂的 反式结构 $\left[\mathrm{RhCl}(\mathrm{CO})\left(\mathrm{PPh}_{3}\right)_{2}\right] 11$ 和不可逆还原消除产物 12 (Scheme15). 该机理得到了其他课题组 ${ }^{[56]}$ 的认可.

在无保护的醛糖中延长或缩短碳链一直是碳水化

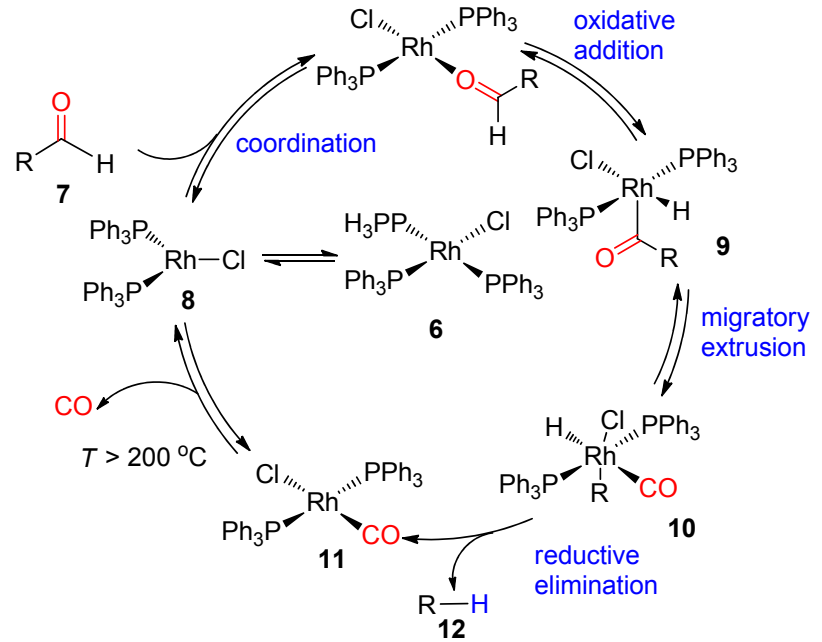

图式 15 铑催化脱羰基可能的机理

Scheme 15 Proposed mechanism of rhodium-catalyzed decarbonylation

合物化学的一个主题. 虽然已有许多方法可应用于醛糖 的链伸长, 但缩短碳链的方法却很少. 2007 年, Madsen 等 ${ }^{[57]}$ 用铑作催化剂, $N, N$-二甲基乙酰胺(DMA)作溶剂, 以中等偏上的产率得到无保护醛糖脱羰基化产物(Eq. 11).

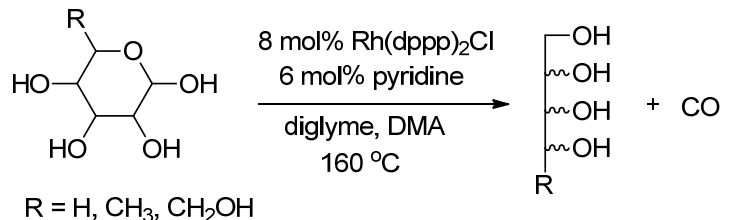

苯并吡喃是合成许多天然产物的中间体，包括大麻 素、花青素和黄酮. 2009 年, Bräse 等 ${ }^{[58]}$ 首次报道了金属 铑催化的 3-甲酰基苯并吡喃脱羰基化反应，并将其应用 在天然产物的合成中(Eq. 12).

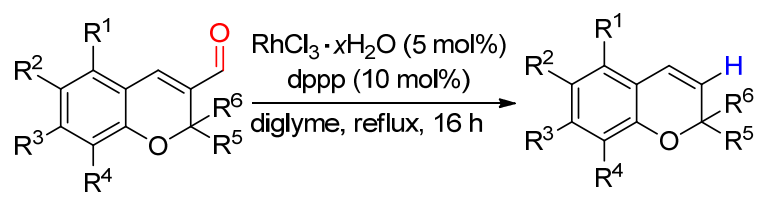

2010 年, Zhao 等 ${ }^{[59]}$ 在铑配体的催化作用下，用 1 equiv. 氢氧化钠作碱, 以水和甲苯的混合溶液作溶剂, 在加热条件下，脱去芳香羧酸中的游离羧基，并将该体 系成功应用于 Heck-Mizoroki 烯基化反应中(Scheme 16). 反应中除生成烯烃芳基化产物外，还生成少量共轭加成 产物.

2015 年，董广涁等 ${ }^{[60]}$ 报道了一种铑配合物催化的 炔基 $\alpha$-二酮脱羰基化反应. 通过使用不同的配体和溶 剂, 可以选择性地实现单或双脱羰基反应, 分别给出共 

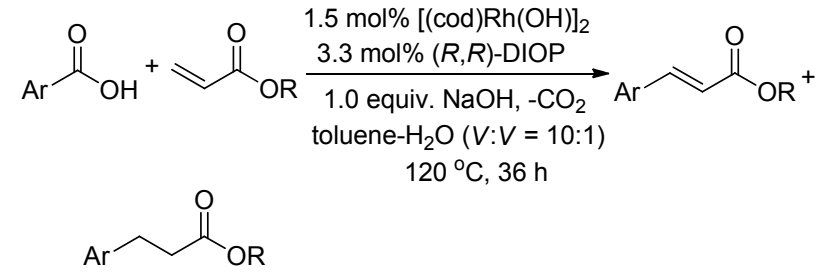<smiles>CCOC(=O)/C=C/c1c(F)cc(F)cc1OCCOC(=O)/C=C/c1c(F)cc(OC)cc1F</smiles>

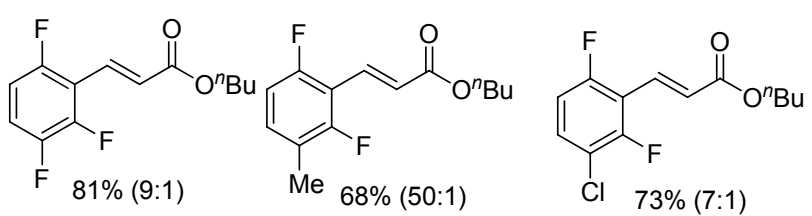<smiles>CCOC(=O)/C=C/c1c(F)c(F)c(F)c(F)c1/C=C/C(=O)OCC</smiles>

图式 16 铑催化脱羰基的应用

Scheme 16 Application of rhodium catalyzed decarbonylation 轭炔酮和双取代的炔烃化合物(Scheme 17). 该反应体 系可同时兼容芳香烃和脂肪烃，有较好的底物适应性.

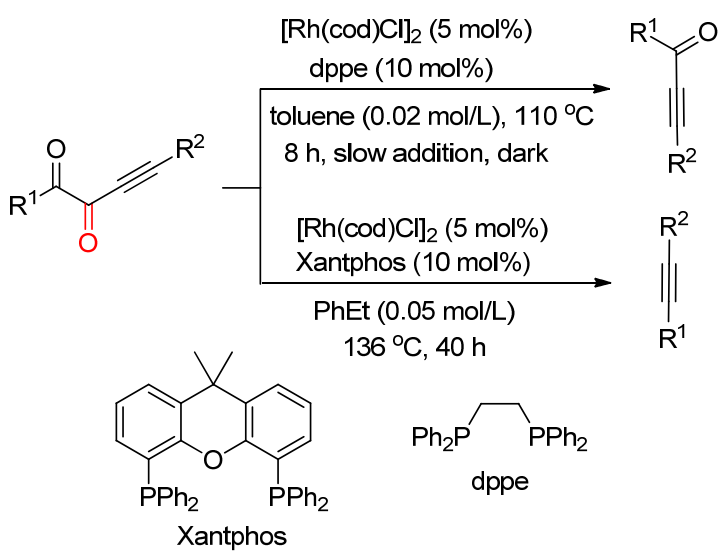

图式 17 铑催化炔基不饱和二酮脱羰基反应

Scheme 17 Rhodium catalyzed decarbonylation of alkynyl unsaturated diketone

\section{$3.2 \mathrm{C}$ - X 键的断裂}

$\mathrm{C}-\mathrm{CN}$ 键的还原异裂的方法不太常见, 而且通常 使用强还原剂 $\left(\mathrm{Na} / \mathrm{NH}_{3}, \mathrm{~K}\right.$ 或 $\left.\mathrm{LiAlH}_{4}\right)$, 所以限制了其实 际应用. 2009 年, Tobisu等 ${ }^{[61]}$ 用铑作催化剂, 以温和的还 原剂 3-异丙基硅烷作氢源, 乙基环已烷作溶剂完成了氭 基化合物的脱氰基反应(Eq. 13), 该反应最高产率达 $99 \%$, 反应有较广的底物范围, 包括芳香㲵化物、含 $\beta-$
氢的伯、仲以及某些具有多种官能团的三芳基烷基氰化 物.

$$
\begin{aligned}
& {[\mathrm{RhCl}(\mathrm{cod})]_{2}(10 \mathrm{~mol} \%)}
\end{aligned}
$$

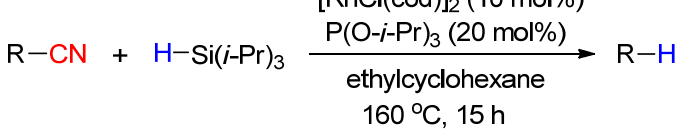

在已建立的芳基甲硫基化合物脱硫方法中，主要局 限于使用化学计量金属还原剂的方法. 2013 年, Willis 等 ${ }^{[62]}$ 用三乙氧基硅烷作氢源，二氯甲烷作溶剂，铑配合 物作催化剂，在温和的条件下得到脱硫产物 (Scheme 18)，产率最高可达 99\%。普适性研究表明有与苯环或杂 环形成共轭体系的原子或化学键存在时, 反应才能顺利 进行，反之则亦然.
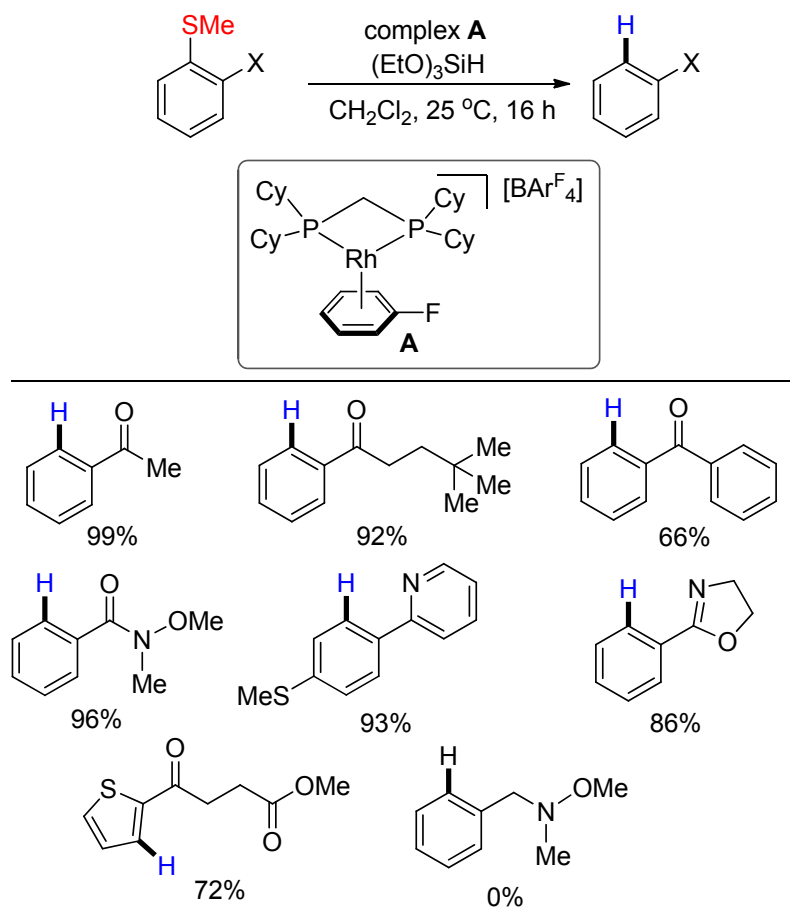

图式 18 铑催化脱硫反应

Scheme 18 Rhodium catalyzed desulfurization

目前蛋白质含量丰富的生物质废弃物主要用于制 备动物饲料，而将其中的氨基酸成分转化为含氮化学物 质是一种潜在的高价值应用途径. 2018 年, De Vos 等 ${ }^{[63]}$ 对氨基酸加氢制氨基醇进行了研究. 该反应以 $\mathrm{Rh}-\mathrm{MoO}_{x} /$ $\mathrm{SiO}_{2}$ 作催化剂, 氢气氛围下, 在 $0.3 \mathrm{~mol} / \mathrm{L}$ 的磷酸溶液中 高收率地将谷氨酸还原加氢得到氨基醇(Eq. 14). 其它 天然氨基酸分子在该体系下也高收率地转化成氨基醇 产物。

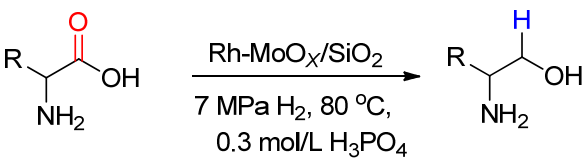




\section{4 钉催化的去官能团化反应}

过渡金属催化在近年来一度成为研究热点. 2001 年, Murai 等 ${ }^{[64]}$ 用甲酸胺作氢源、1,4-二氧六环作溶剂, 在钉催化剂作用下，高产率地完成了脱羰基化反应(Eq. 15), 反应普适性较好. 反应中若不加入 $\mathrm{HCOONH}_{4}$, 则 不能顺利进行, 说明 $\mathrm{HCOONH}_{4}$ 的加入对反应的发生是 至关重要的. 以铑配合物作催化剂, 脱羰基化 ${ }^{[65]}$ 和脱羟 甲基化 ${ }^{[6]}$ 陆续被发展.

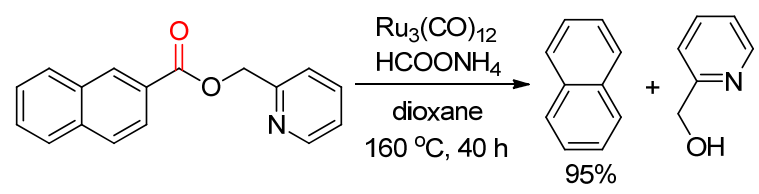

一些过渡金属复合物可以促进醇的氢化或硅烷化, 从而产生相应的乙烯基硅烷产物. 钓催化的 $\mathrm{C}-\mathrm{O}$ 键的 断裂近年来鲜有报道. 2006 年, Nishibayashi 等 ${ }^{[67]}$ 对炔基 $\alpha$-醇脱羟基化进行了研究. 过渡金属催化硅氢化反应的 选择性取决于催化剂、底物、硅烷和溶剂的性质. 该反 应在以钉配合物作催化剂、三乙基硅烷提供质子、二氯 乙烷作溶剂的条件下得到炔基 $\alpha$-醇脱羟基的目标产物 (Eq. 16). 若减少氢源的量, 或改变氢源都会导致产率降 低或者反应不能发生. 在醇脱氧化领域, 长期存在的科 学挑战是反应的选择性差、效率低等缺点.

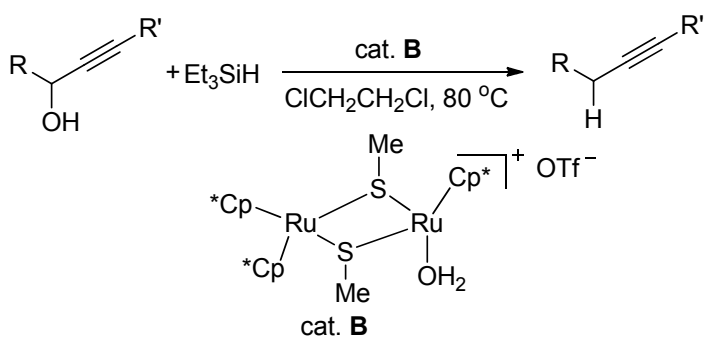

直接催化使分子中同时存在其他官能团的羟基化 合物(如在生物分子中广泛存在的自由羟基和胺基等官 能团)的 $\mathrm{C}\left(\mathrm{sp}^{3}\right)-\mathrm{O}$ 键断裂, 大都需要苛刻的条件, 因而 限制了其在合成中的应用. 2016 年, $\mathrm{Li}$ 等 ${ }^{[68]}$ 利用钉配合 物进行脂肪族伯醇脱氧化的研究取得了重大进展, 在较 温和的条件下得到了天然药物分子脱羟基化目标产物 (Scheme 19). 在底物的普适性研究中发现该反应具有 良好的官能团耐受性和专一选择性, 说明该反应具有良 好的合成用途.

许多有机分子对可见光只有弱吸收, 进而限制了这 些分子在光催化中的应用. 光敏剂的发现解决了这一问 题. 光催化近年来一直是有机合成领域的热点, 但其在 去官能团化中的应用不多. 2009 年, Stephenson 等 ${ }^{[69]}$ 在 光催化和钉复合物光敏剂作用下以较高的收率得到了

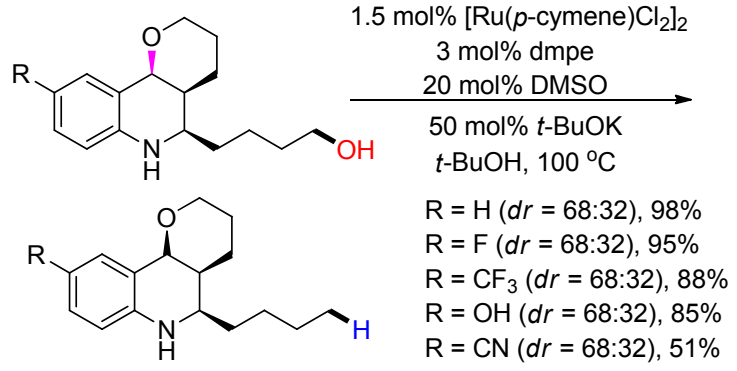

图式 19 钉催化的天然药物分子脱羟基反应

Scheme 19 Ruthenium catalyzed dehydroxylation of natural drug molecules

脱卤化产物. 在同位素标记实验中，以気代甲醇替代甲 醇，其余条件不变，只得到了 $20 \%$ 的忥代产物，证明反 应中提供氢源的主要物质可能是 ${ }^{i} \operatorname{Pr}_{2}$ NEt. 2017 年, 夏远 志等 ${ }^{[70]}$ 发展了一种简单有效的脱卤化反应, 以 $\left[\operatorname{RuCl}_{2}(p \text {-cymene })\right]_{2}(p$-cymene $=$ 对异丙基甲苯 $)$ 作催化 剂，芳基卤化物和 $\alpha$-溴代羰基化合物生成脱卤化产物. 在提出的可能的机理中(Scheme 20$),\left[\mathrm{RuCl}_{2}(p \text {-cymene) }]_{2}\right.$ 经过配体解离、氧化加成得到中间体 $\mathbf{1 3}$, 而后在碱的作 用下异丙醇插入得到 14 , 接着脱离一分子的丙酮得到 15 , 最后经过还原消除在得到目标产物的同时实现催化 剂的循环使用.

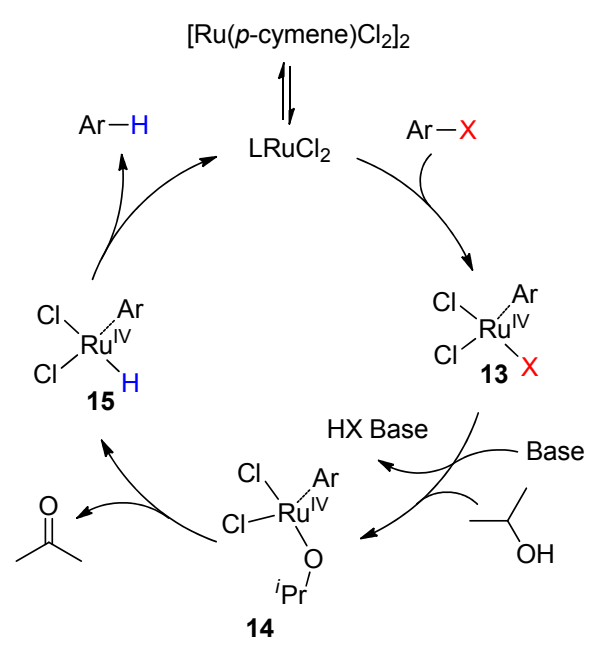

图式 $20 \quad\left[\mathrm{RuCl}_{2} \text { (cymene) }\right]_{2}$ 催化脱卤反应可能的机理 Scheme 20 Proposed mechanism of $\left[\mathrm{RuCl}_{2}(\mathrm{cymene})\right]_{2}$ catalyzed dehalogenation

\section{5 铜催化的去官能团化反应}

铜在地球储量较丰富，其廉价易得无毒的性质促进 了其在有机合成中的应用 ${ }^{[71]}$. 铜催化的去官能团化反 应在近年来陆续得到了发展.

近年来, 各种金属催化的脱羧反应 ${ }^{[2]}$ 成为了热门 研究领域. Gooßen ${ }^{[73]}$ 以及 Goossen ${ }^{[74]}$ 等利用铜催化实现 了羧基取代的芳烃化合物的脱羧反应. 2013 年, Cahiez 等 ${ }^{[75]}$ 以氧化亚铜作催化剂, 在 $N, N, N^{\prime}, N^{\prime}$-四甲基乙二胺 
(TMEDA)的作用下脱去了带有吸电子基芳香族化合物 的羧基(Scheme 21). 该反应底物范围广, 能容忍各类官 能团, 且在较前人工作稍低的温度下进行, 高效快速, 最高以 $99 \%$ 的产率得到目标产物.

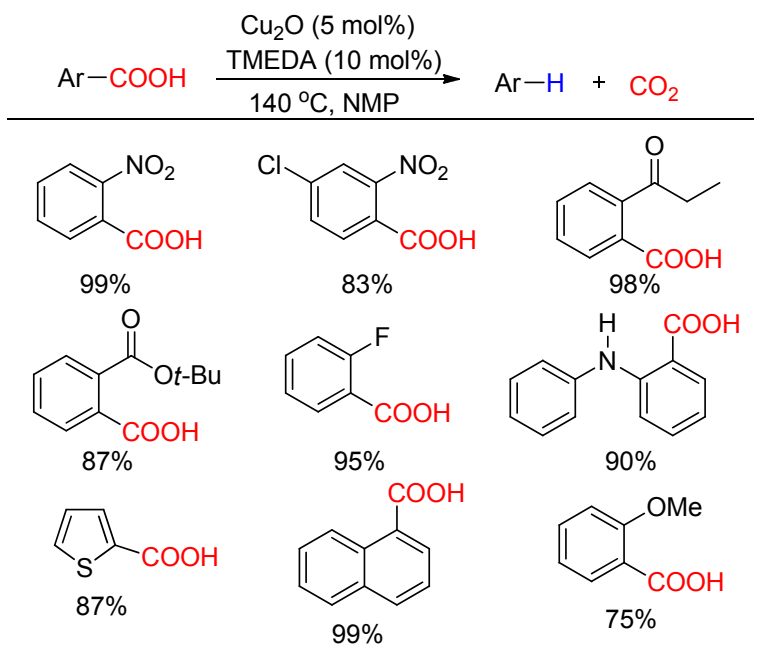

图式 21 铜催化脱羧反应

Scheme 21 Copper catalyzed decarboxylation

由于其成本低、无害、稳定性高和容易获得的性质, 羧酸和羧酸盐是合成有机化学中有价值的起始原料, 用 于生产高价值的产品. 2016 年, 蔡琥等 ${ }^{[76]}$ 用碘化亚铜作 催化剂, 在三乙胺作用下, 以较高的产率得到脱羧产物 (Scheme 22). 该反应需在氮气氛围下进行, 在空气中不 能发生反应, 若降低温度该反应的产率也相应降低, 改 变溶剂反应产率也同样降低或不发生反应.
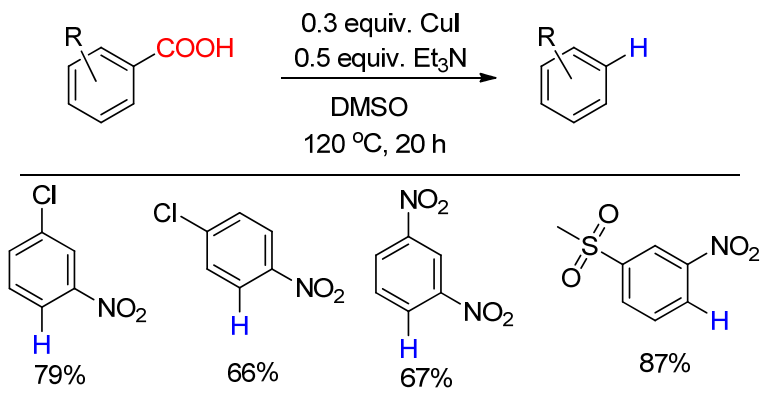

图式 22 碘化亚铜催化脱羧反应

Scheme 22 Cuprousr iodide catalyzed protodecarboxylation

酯是常见的有机合成结构单元, 广泛存在于天然产 物中. 因此, 酯类化合物的还原在合成有机化学中是非 常重要的. 2018 年, Busca 等 ${ }^{[77]}$ 首次发展了一种无需气体 保护和溶剂, 醋酸铜作催化剂, 芳香和杂芳香羧酸酯的 脱官能团化反应(Scheme 23). 这种新的反应使用一种 廉价、无毒、对水和空气都稳定的醋酸铜作催化剂, 与 廉价的菲罗啉配体结合, 在相对温和的条件下得到目标
产物. 在该反应的机理中，醋酸铜在喹啉的作用下形成 具有催化活性的复合物 16 , 苯甲酸甲酯在亲核溶剂的 作用下先脱去甲基，形成铜的苯甲酸盐 17 , 然后脱羧形 成过渡态 18, 随后金属插入芳基-羧酸键中，并形成苯 基铜盐 19, 最后喹啉作为主要氢源得到目标产物.

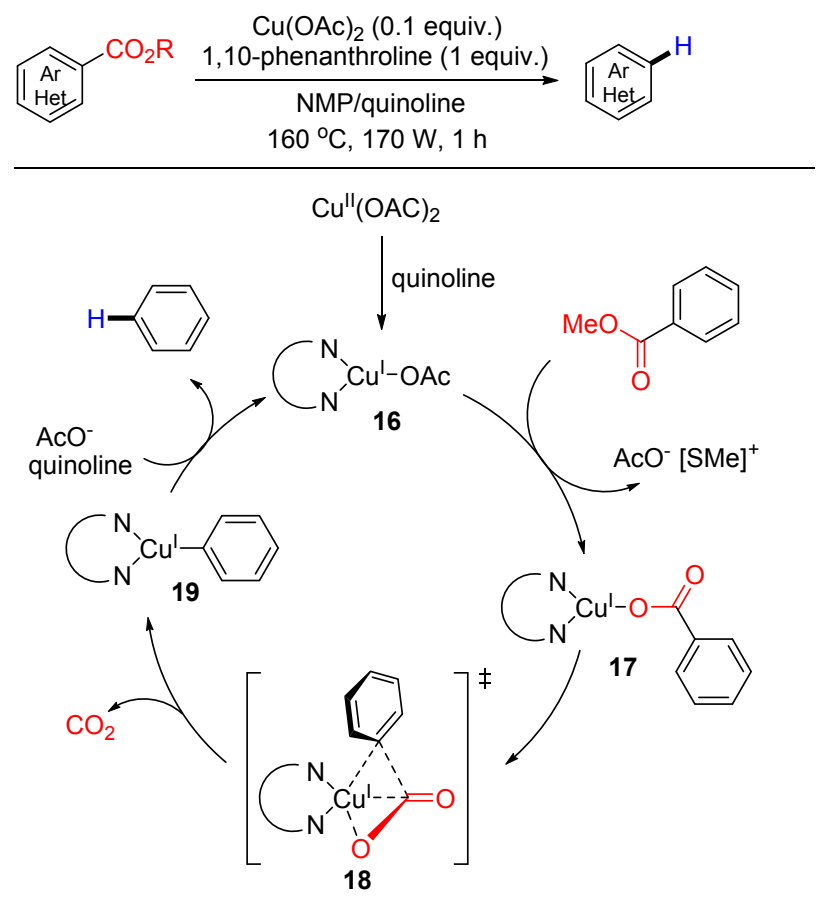

图式 23 醋酸铜催化脱酯可能的机理

Scheme 23 Proposed mechanism of copper acetate catalyzed proto-decarbomethoxylation

\section{6 铁催化的去官能团化反应}

$\mathrm{C}-\mathrm{C}$ 键的断裂依旧是具有挑战的课题, 尤其是活 化的腈类化合物的 $\mathrm{C}-\mathrm{CN}$ 键的断裂，因为 $\mathrm{C}-\mathrm{CN}$ 键的 键能 $\left(555.9 \mathrm{~kJ} \cdot \mathrm{mol}^{-1}\right)$ 较烷烃 $\mathrm{C}-\mathrm{C}$ 键的键能 $(346.9 \mathrm{~kJ} \cdot$ $\left.\mathrm{mol}^{-1}\right)$ 高, 键的断裂需要吸收更高的能量. 2005 年, Nakazawa 等 ${ }^{\left[{ }^{78]}\right.}$ 用三乙基硅烷作质子源, 发展了一种铁 催化 $\mathrm{C}-\mathrm{CN}$ 键断裂的反应，脂肪族和芳香族的腈类化 合物在该体系中成功地脱去氧基. 根据他们提出的机 理, $\mathrm{Cp}(\mathrm{CO}) \mathrm{FeMe}$ 是由 $\mathrm{Cp}(\mathrm{CO})_{2} \mathrm{FeMe}$ 光解产生, 接着 $\mathrm{Cp}(\mathrm{CO}) \mathrm{FeMe}$ 与三乙基硅烷作用生成 $\mathrm{Cp}(\mathrm{CO}) \mathrm{FeMe}-$ $(\mathrm{H})\left(\mathrm{SiEt}_{3}\right)$. 在连续还原消除后形成了脱氰基产物，并产 生活性物种 $\mathrm{Cp}(\mathrm{CO}) \mathrm{Fe}\left(\mathrm{SiEt}_{3}\right.$ ) 继续催化循环( $\left.\mathrm{Scheme} 24\right)$.

由于 $\mathrm{C}-\mathrm{O}$ 键的高键能, 铁催化的 $\mathrm{C}-\mathrm{O}$ 键的断裂 需要吸热, 所以通常需要通过加热或加碱等方式才能实 现. 2016 年, Bi 等 ${ }^{[79]}$ 发展了 2 -硝基苯磺酰肼(NBSH)介导 的 $\mathrm{FeF}_{3}$ 和三氟甲磺酸 $(\mathrm{TfOH})$ 共催化不饱和烃醇还原脱 氧反应(Scheme 25). 该反应有高的立体选择性和区域 选择性，当底物中含有䒺、噻吩、三元环、六元环时反 应也可在温和的条件下顺利进行. 


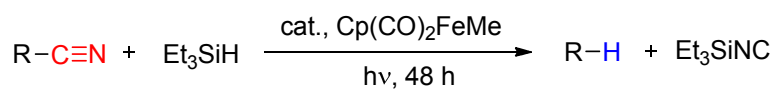

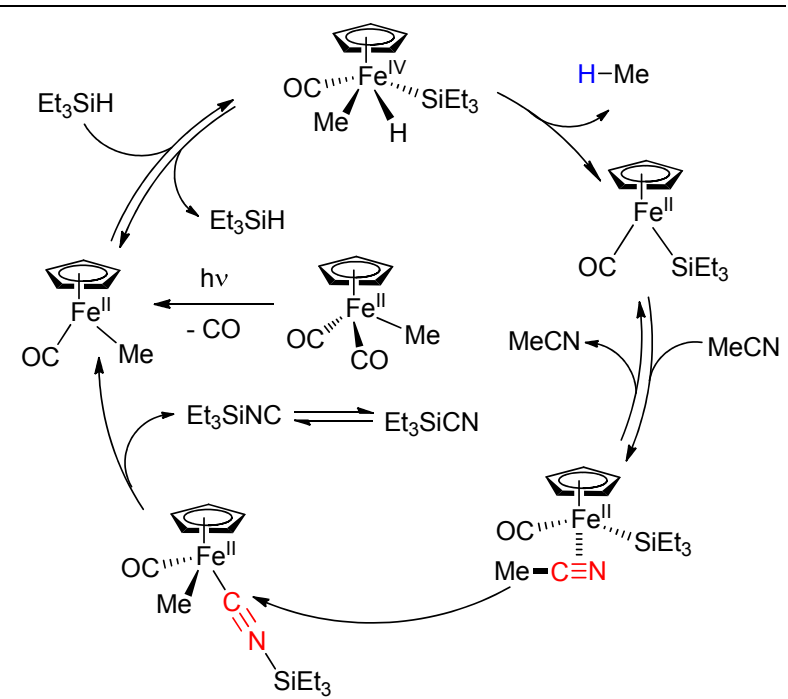

图式 $24 \mathrm{Cp}(\mathrm{CO})_{2} \mathrm{FeMe}$ 催化还原脱氧基反应可能的机理

Scheme 24 Proposed mechanism for $\mathrm{Cp}(\mathrm{CO})_{2} \mathrm{FeMe}$ catalyzed reductive decyanation

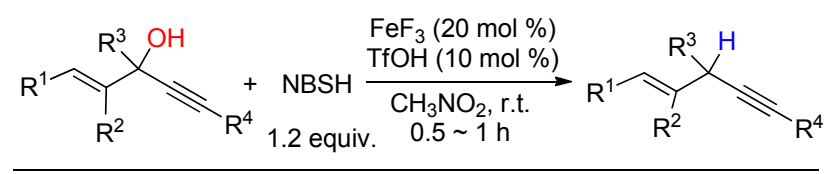<smiles>C#CC(/C=C/c1ccccc1)c1ccccc1</smiles>

$89 \%$<smiles>CCCC#CC=Cc1ccccc1</smiles><smiles>CC(C)(C)C#CC(/C=C/c1ccccc1)c1ccccc1</smiles>
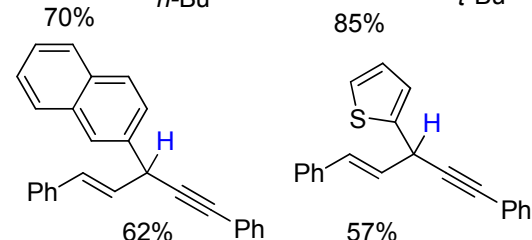

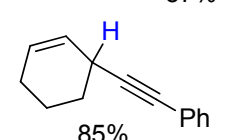

$85 \%$

图式 $25 \mathrm{FeF}_{3}$ 催化还原脱氧反应

Scheme $25 \quad \mathrm{FeF}_{3}$ catalyzed reductive deoxygenation

\section{7 铱催化的去官能团化反应}

铱作为过渡金属中重要的一种金属, 同样被用于去 官能团化反应中. 2008 年, Tsuji 等 ${ }^{[80]}$ 发展了一种脱醛基 化反应，并且利用铱的不同配体，定向地脱去芳基和芳 基衍生物中的羰基(Scheme 26). 反应以 1,4-二氧六环作 溶剂, 三苯基磷作配体, 当改变溶剂或配体时, 反应的 产率都有所降低. 2013 年, $\mathrm{Li}$ 等 ${ }^{[81]}$ 首次以铱作催化剂, 实现了醇直接脱羟基化形成 $\mathrm{C}-\mathrm{H}$ 键. 伯醇、芐醇以及 烯醇在水合肼的作用下脱去羟基(Scheme 27). 2018 年, 许家喜等 ${ }^{[82]}$ 在铱催化剂下以甲酸作氢源, 在温和条件

下同样得到了伯、仲、叔醇脱氧化产物。该反应相对于 $\mathrm{Li}$ 等工作的优点在于反应温度较低, 条件较温和.

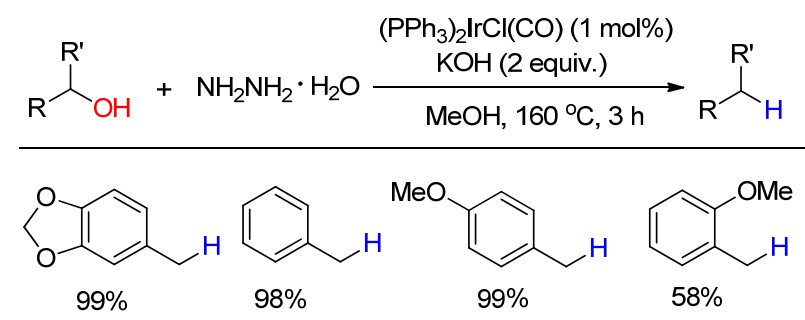

图式 26 铱催化芳基醛的脱羰基反应

Scheme 26 Iridium catalyzed decarbonylation of aryl aldehydes

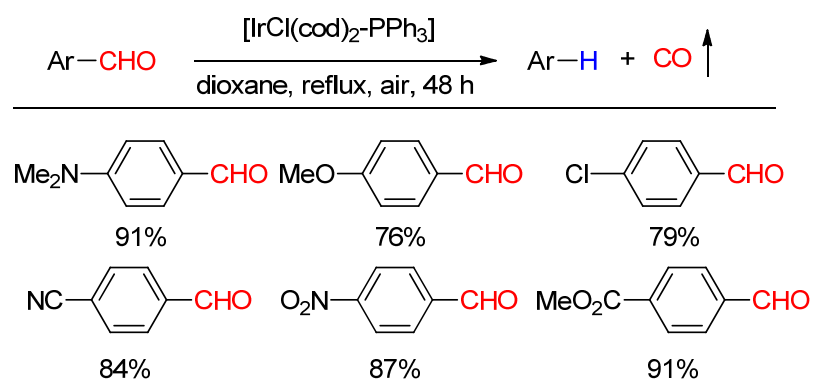

图式 27 铱催化茮醇的还原脱氧反应

Scheme 27 Iridium catalyzed reductive deoxygenation of benzyl alcohol

木质素是连接纤维素与半纤维素的纽带. 经过研究 发现，木质素是一种比较复杂的三维网状苯丙烷基高聚 物，是目前已知的唯一可再生的含有芳香族化合物的资 源，并且木质素具有碳中性、可降解性和可再生等优势, 也是最有希望在将来代替石油和煤炭成为芳香化合物 的来源的物质. 2013 年, Stephenson 等 ${ }^{[83]}$ 在三价铱光敏 剂以及可见光作用下，以乙腈作溶剂在常温下得到木质 素模型分子降解的目标产物(Eq. 17).

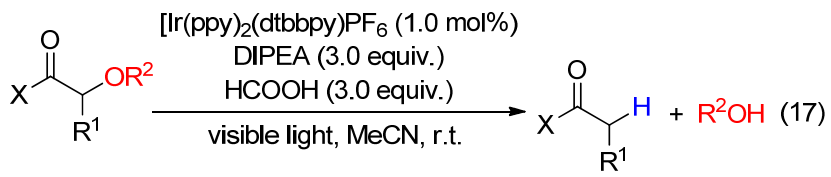

\section{8 银催化的去官能团化反应}

脱羧反应是有机合成上重要的一个转化. 2009 年, Larrosa 等 ${ }^{84]}$ 发展了一种以碳酸银作氧化剂、以乙酸作 为质子源、以二甲基亚砜作溶剂的选择性脱羒反应. 经 过进一步的研究, 2012 年, 该课题组 ${ }^{[85]}$ 同样以碳酸银作 催化剂，发展了一种芳香族羧酸化合物的脱羧反应，该 反应是以水作为质子源. 在底物的普适性研究中, 发现 不论是吸电子基还是给电子基取代的羧酸化合物都能 以良好到优秀的产率得到目标产物(Scheme 28). 


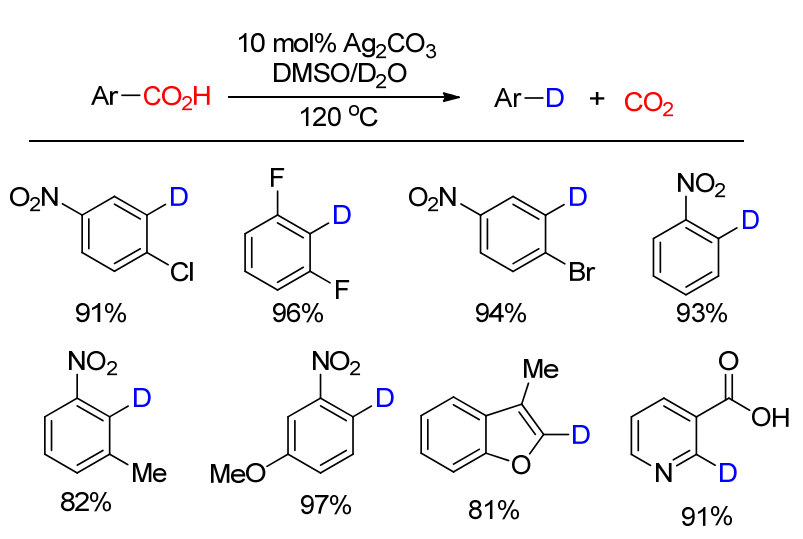

图式 28 银催化的脱羧反应

Scheme 28 Siliver-catalyzed decarboxylation

2012 年, Greaney 等 ${ }^{[86}$ 在醋酸银的作用下, 以过硫 酸钾作氧化剂, 乙腈作溶剂, 得到脱羧产物. 在给出的 可能的机理中, 氧化的 $\operatorname{Ag}(\mathrm{II})$ 将羧化物 20 原位氧化为自 由基 21, 芳香族脱羧比烷基化合物的脱䍨更慢, 所以需 要在较为苛刻的条件中进行. 在该法中, 作者仅使用银 催化剂, 在 $100{ }^{\circ} \mathrm{C}$ 下失去一分子二氧化碳得到自由基 22, 最后乙腈的氢原子转移得到最终的目标产物 23 (Scheme 29).

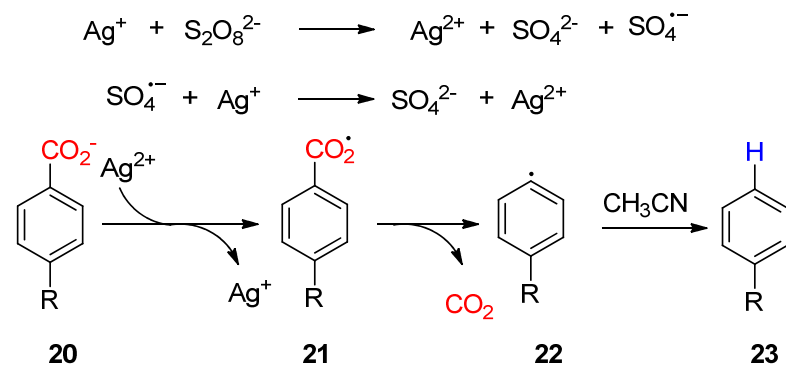

图式 29 银催化脱羧可能的机理

Scheme 29 Proposed mechanism of silver catalyzed decarboxylation

\section{9 其他金属催化的去官能团化反应}

其他金属催化的去官能团化研究的较少，还有待发 展. 钴常有的化合价为 +2 价和 +3 价, 在常温下不和水 作用, 在潮湿的空气中也很稳定. 由电极电势看出, 钴 是中等活泼的金属. 其化学性质与铁、镍相似. 2015 年, Siegbahn 等 ${ }^{[87]}$ 探究了钴催化的芳香族化合物脱卤化的 机理. 2014 年, 王健吉等 ${ }^{[88]}$ 用乙酰丙酮钴作催化剂, 以 四氢铝锂作还原剂实现了醚键断裂(表 1). 带各种官能 才的芳基醚都以高收率得到还原脱氧产物.

铝介导的去官能团化主要应用在脱羟基化反应 中 $^{[89]}$, 且在近年来研究的较少. 钼作为稀有金属, 在去 官能团化的发展中也崭露头角. 钼催化的去官能团化在 近年来主要是脱氧化反应, 2012 年, Sanz 等 ${ }^{[90]}$ 利用钼催
表 1 钴催化醚键的断裂

Table 1 Fracture of ether bonds catalyzed by cobalt

(-BuONa, toluene, $140^{\circ} \mathrm{C}, 24 \mathrm{~h}$

化剂使亚砜还原脱氧得到硫醚类化合物(Scheme 30). 反应使用 2,3-二甲基-2,3-丁二醇作为氢源，且不论是对 称亚砜还是不对称亚砜都在该条件下以优良的产率得 到目标产物. 2016 年, Fernandes 等 ${ }^{[91]}$ 报道了一种高效的 二芳基酮和苯乙酮还原脱氧的方法，在二氧化钼配合物 的催化下，以硅烷为还原剂，生成相应的烷烃(Scheme

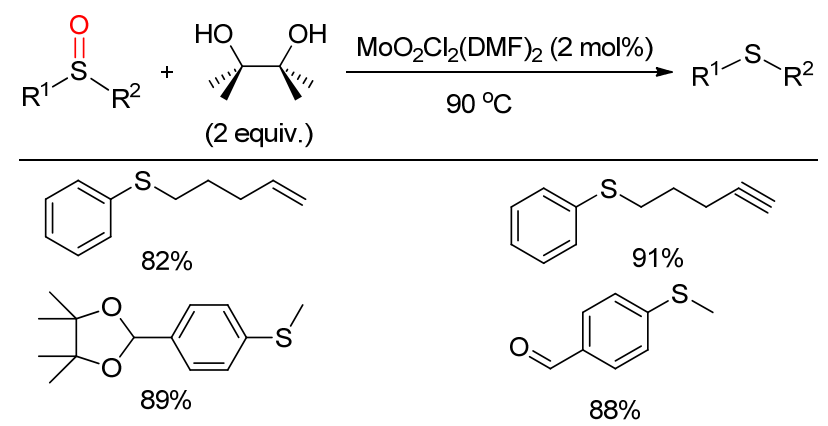

图式 30 钼催化亚砜的脱氧反应

Scheme 30 Molybdenum catalyzed deoxygenation of sulfoxide 
31). 该方法避免使用了贵金属催化剂，底物范围广，最 高产率可达 98\%.

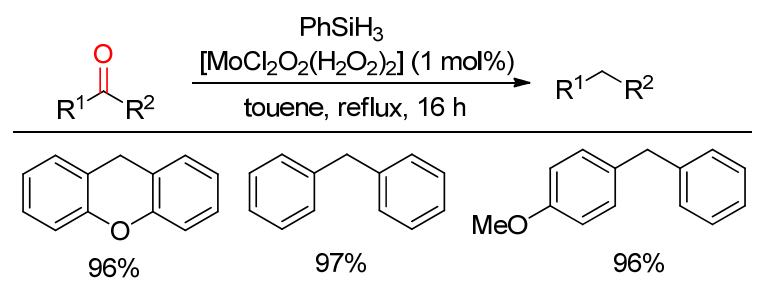

图式 31 钼催化羰基脱氧化反应

Scheme 31 Molybdenum catalyzed carbonyl deoxygenation

金作为装饰品在日常生活中最为常见. 由于其价格 昂贵, 近年来在有机合成中的应用较少, 在去官能团化 反应中主要应用于脱羧反应 ${ }^{[92]}$.

2001 年, $\mathrm{Baba}$ 等 ${ }^{[93]}$ 以二苯基氯硅烷为氢源, 在三氯 化铟的催化作用下直接还原醇类化合物(Eq. 18). 在该 反应中伯醇、仲醇和叔醇都高产率地转化为目标产物. 三氯化铟作为路易斯酸加速氢化物转移继而加速脱氧. 2007 年, Hosomi 等 ${ }^{[94]}$ 以醋酸铟作催化剂, 在不同氢源或 还原剂的作用下得到了脱卤化产物.

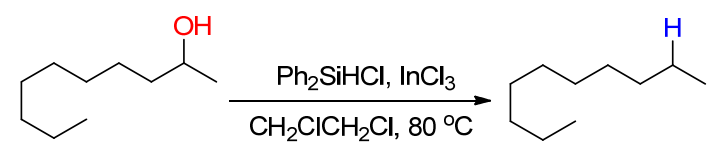

2017 年, Milstein 等 ${ }^{[95]}$ 发展了一种金属锰螯合物作 催化剂的反应, 在叔丁醇钾作用下茮基醇脱去差基. 通 过进一步的研究, 该课题组 ${ }^{[96]}$ 用同样的催化剂, 在路易 斯酸和氢气作用下得到了酰胺化合物中羰基脱氧化产 物(Scheme 32).
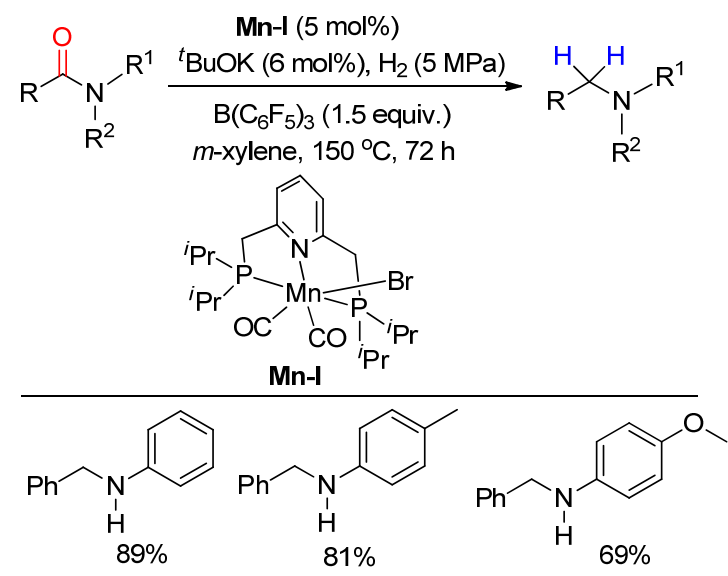

图式 32 锰催化酰胺脱氧反应

Scheme 32 Manganese catalyzed deoxygenation of amide

丞催化 ${ }^{[97]}$ 的脱羧反应、钛催化 ${ }^{[98]}$ 的脱羟基化反应、 钲介导 ${ }^{[99]}$ 的炔醇脱羟基化反应以及以碳酸铯作碱 ${ }^{[100]}$ 的 分子内脱羧反应陆续得以发展.

\section{0 非金属的去官能团化反应}

硼催化的去官能团化反应在 21 世纪初就有报道 ${ }^{[101]}$. 2002 年, Chandrasekhar 等 ${ }^{[102]}$ 利用 PMHS-B $\left(\mathrm{C}_{6} \mathrm{~F}_{5}\right)_{3}$ (PMHS：聚甲基氢硅氧烷)作催化剂, 室温下得到羰基 脱氧化产物(表 2). 在该反应中芳香族和脂肪族羰基化 合物都被有效还原，得到相应的烷烃，最高以 $96 \%$ 的收 率得到目标产物.

\section{表 2 嗍催化羰基脱氧反应}

Table 2 Boron catalyzed carbonyl deoxygenation

Entry

苯乙酸是一类重要的化合物, 广泛存在于医药和天 然产物中. 它们表现出多种多样的生物特性，包括抗 炎、抗真菌、抗酪氨酸酶和抗菌活性. 因而得到了科学 家们的广泛关注. 2011 年, Milne 等 ${ }^{[103]}$ 通过碘化钠原位 生成氢碘酸，磷酸作还原剂简单地合成了苯乙酸 (Scheme 33). 在甲磺酸(MAS)的作用下, 该反应底物范 围广, 条件较为温和, 收率高. 2012 年, 刘玉环等 ${ }^{[04]}$ 利 用微波加热促使硬脂酸钠脱羧. 脂肪族的光氧化脱酸是 相对较难实现的, 2015 年, Nicewicz 等 ${ }^{[105]}$ 在 $450 \mathrm{~nm}$ 的 LED 灯的作用下, 实现了非金属催化的还原脱羧 (Eq. 19). 该反应提供了一个直接的有机催化过程，将羧酸 
脱羧为烷烃, 包括通过其他方法不能脱羧的一些羧酸底

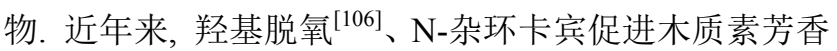
酸衍生物脱羧 ${ }^{[107]}$ 、三氯化磷催化亚砜脱氧生成硫 醚 ${ }^{[108]}$ 、卤素芳香化合物脱卤反应 ${ }^{[109]}$ 相继被报道, 非金 属催化的去官能团化将得到更进一步的发展.
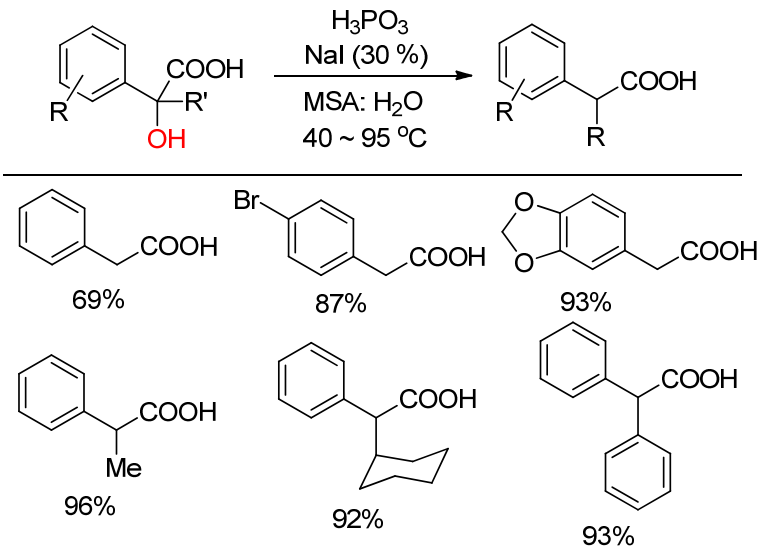

图式 33 碘化钠催化苯乙酸的合成

Scheme 33 Synthesis of phenylacetic acid catalyzed by sodium iodide

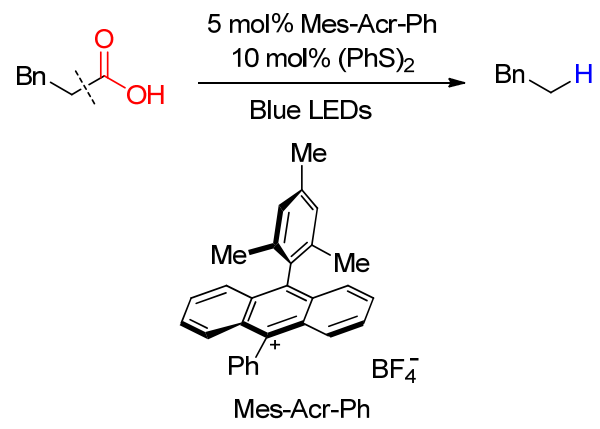

\section{1 结论与展望}

去官能团化, 即碳一碳/杂原子键裂解策略. 近年来, 去官能团化, 即碳一碳/杂原子键裂解策略, 正朝着使用 价廉的过渡金属催化剂、环境友好的绿色还原剂, 发展 温和的反应条件和拓展广泛的底物范围等方向快速发 展, 也是去官能团化当前的研究重点. 由于去官能团 化在不同领域有广泛应用，长期以来一直是有机合成 中的研究热点. 现如今, 全球性资源危机和环境问题 日益加剧, 在此情况下, 去官能团化显得尤为重要. 更 有效的去官能团化手段的出现, 将为从生物质等可再 生资源中寻找能源生产的新途径发挥重要作用. 同时, 去官能团化在塑料降解和药物开发等领域的潜在应用 还有待探索. 因此, 发展实用的去官能团化方法并应 用于实际生产将成为化学家们未来的一大挑战.

\section{References}

[1] Modak, A.; Maiti, D. Org. Biomol. Chem. 2016, 14, 21.
[2] Verduyckt, J.; Van Hoof, M.; De Schouwer, F.; Wolberg, M.; Kurttepeli, M.; Eloy, P.; Gaigneaux, E. M.; Bals, S.; Kirschhock, C. E. A.; De Vos, D. E. ACS Catal. 2016, 6, 7303.

[3] Ferrini, P.; Chesi, C.; Parkin, N.; Rinaldi, R. Faraday Discuss. 2017, 202, 403.

[4] Takise, R.; Muto, K.; Yamaguchi, J. Chem. Soc. Rev. 2017, 46, 5864.

[5] Matsubara, S.; Yokota, Y.; Oshima, K. Org. Lett. 2004, 6, 2071.

[6] Dickstein, J. S.; Mulrooney, C. A.; O'Brien, E. M.; Morgan, B. J.; Kozlowski, M. C. Org. Lett. 2007, 9, 2441

[7] Ladwein, K. I.; Jung, M. Angew. Chem., Int. Ed. 2011, 50, 1214

[8] Modak, A.; Naveen, T.; Maiti, D. Chem. Commun. 2013, 49, 252.

[9] Modak, A.; Deb, A.; Patra, T.; Rana, S.; Maity, S.; Maiti, D. Chem. Commun. 2012, 48, 4253.

[10] Akanksha; Maiti, D. Green Chem. 2012, 14, 2314.

[11] (a) Huang, Y.-B.; Yang, Z.; Chen, M.-Y.; Dai, J.-J.; Guo, Q.-X.; Fu, Y. ChemSusChem 2013, 6, 1348

(b) Chatterjee, M.; Ishizaka, T.; Kawanami, H. Green Chem. 2018, 20, 2345.

[12] Li, W.-H.; Li, C.-Y.; Li, Y.; Tang, H.-T.; Wang, H.-S.; Pan, Y.-M.; Ding, Y.-J. Chem. Commun. 2018, 54, 8446.

[13] Ogiwara, Y.; Sakurai, Y.; Hattori, H.; Sakai, N. Org. Lett. 2018, 20 , 4204.

[14] Dawes, G. J. S.; Scott, E. L.; Le Nôtre, J.; Sanders, J. P. M.; Bitter, J. H. Green Chem. 2015, 17, 3231.

[15] Si, Y.-G.; Gardner, M. P.; Tarazi, F. I.; Baldessarini, R. J.; Neumeyer, J. L. J. Med. Chem. 2008, 51, 983.

[16] Cao, D.; Zeng, H.; Li, C.-J. ACS Catal. 2018, 8, 8873.

[17] Sawadjoon, S.; Lundstedt, A.; Samec, J. S. M. ACS Catal. 2013, 3, 635.

[18] Ritter, K. Synthesis 1993, 735.

[19] Pan, Y.; Holmes, C. P. Org. Lett. 2001, 3, 2769.

[20] Sajiki, H.; Mori, A.; Mizusaki, T.; Ikawa, T.; Maegawa, T.; Hirota, K. Org. Lett. 2006, 8, 987.

[21] Mori, A.; Mizusaki, T.; Ikawa, T.; Maegawa, T.; Monguchi, Y.; Sajiki, H. Chem.-Eur. J. 2007, 13, 1432.

[22] Hupp, C. D.; Neumeyer, J. L. Tetrahedron Lett. 2010, 51, 2359

[23] Chow, W. K.; So, C. M.; Lau, C. P.; Kwong, F. Y. Org. Chem. Front. 2014, 1, 464.

[24] Graham, T. H.; Liu, W.; Shen, D.-M. Org. Lett. 2011, 13, 6232.

[25] Matsumura, T.; Niwa, T.; Nakada, M. Tetrahedron Lett. 2012, 53, 4313.

[26] Matsumura, T.; Nakada, M. Tetrahedron Lett. 2014, 55, 1412.

[27] Ishihara, S.; Ido, A.; Monguchi, Y.; Nagase, H.; Sajiki, H. J. Hazard. Mater. 2012, 229, 15 .

[28] Chelucci, G.; Baldino, S.; Ruiu, A. J. Org. Chem. 2012, 77, 9921.

[29] Kashihara, M.; Yadav, M. R.; Nakao, Y. Org. Lett. 2018, 20, 1655

[30] Deng, G.; Chen, J.; Sun, W.; Bian, K.; Jiang, Y.; Loh, T.-P. Adv. Synth. Catal. 2018, 360, 3900.

[31] Patra, T.; Agasti, S.; Akanksha; Maiti, D. Chem. Commun. 2013 $49,69$.

[32] Patra, T.; Agasti, S.; Modak, A.; Maiti, D. Chem. Commun. 2013, 49, 8362.

[33] Enthaler, S.; Weidauer, M.; Irran, E.; Epping, J. D.; Kretschmer, R.; Someya, C. I. J. Organomet. Chem. 2013, 745, 262.

[34] Crawford, J. M.; Shelton, K. E.; Reeves, E. K.; Sadarananda, B. K.; Kalyani, D. Org. Chem. Front. 2015, 2, 726.

[35] (a) Morioka, T.; Nishizawa, A.; Furukawa, T.; Tobisu, M.; Chatani, N. J. Am. Chem. Soc. 2017, 139, 1416.

(b) Somerville, R. J.; Martin, R. Angew. Chem., Int. Ed. 2017, 56, 6708.

[36] Ding, K.; Shi, X.; Alotaibi, R.; Paudel, K.; Reinheimer, E. W.; Weatherly, J. J. Org. Chem. 2017, 82, 4924.

[37] Yu, R.; Chen, X.; Martin, S. F.; Wang, Z. Org. Lett. 2017, 19, 1808.

[38] Yue, H.; Guo, L.; Lee, S.-C.; Liu, X.; Rueping, M. Angew. Chem., Int. Ed. 2017, 56, 3972.

[39] Dey, A.; Sasmal, S.; Seth, K.; Lahiri, G. K.; Maiti, D. ACS Catal. 2017, 7, 433 
[40] Zhao, T.-T.; Xu, W.-H.; Zheng, Z.-J.; Xu, P.-F.; Wei, H. J. Am. Chem. Soc. 2018, 140, 586.

[41] Herrmann, J. M.; König, B. Eur. J. Org. Chem. 2013, 2013, 7017.

[42] Lipshutz, B. H.; Frieman, B. A.; Butler, T.; Kogan, V. Angew. Chem., Int. Ed. 2006, 45, 800.

[43] Álvarez-Bercedo, P.; Martin, R. J. Am. Chem. Soc. 2010, 132, 17352.

[44] Tobisu, M.; Yamakawa, K.; Shimasaki, T.; Chatani, N. Chem. Commun. 2011, 47, 2946.

[45] Cornella, J.; Gómez-Bengoa, E.; Martin, R. J. Am. Chem. Soc. 2013, 135, 1997.

[46] Tobisu, M.; Morioka, T.; Ohtsuki, A.; Chatani, N. Chem. Sci. 2015, $6,3410$.

[47] Sergeev, A. G.; Hartwig, J. F. Science 2011, 332, 439.

[48] Sergeev, A. G.; Webb, J. D.; Hartwig, J. F. J. Am. Chem. Soc. 2012, 134,20226

[49] Li, J.; Wang, Z.-X. Chem. Commun. 2018, 54, 2138.

[50] Cao, Z.-C.; Shi, Z.-J. J. Am. Chem. Soc. 2017, 139, 6546.

[51] Lipshutz, B. H.; Tomioka, T.; Sato, K. Synlett 2001, 970.

[52] Barbero, N.; Martin, R. Org. Lett. 2012, 14, 796.

[53] Tobisu, M.; Nakamura, K.; Chatani, N. J. Am. Chem. Soc. 2014, 136. 5587.

[54] Kreis, M.; Palmelund, A.; Bunch, L.; Madsen, R. Adv. Synth. Catal. 2006, 348, 2148.

[55] Fristrup, P.; Kreis, M.; Palmelund, A.; Norrby, P.-O.; Madsen, R. J. Am. Chem. Soc. 2008, 130, 5206.

[56] Gutmann, B.; Elsner, P.; Glasnov, T.; Roberge, D. M.; Kappe, C. O. Angew. Chem., Int. Ed. 2014, 53, 11557.

[57] Monrad, R. N.; Madsen, R. J. Org. Chem. 2007, 72, 9782.

[58] Bröehmer, M. C.; Volz, N.; Bräese, S. Synlett 2009, 1383.

[59] Sun, Z.-M.; Zhang, J.; Manan, R. S.; Zhao, P. J. Am. Chem. Soc. 2010, 132, 6935.

[60] Whittaker, R. E.; Dong, G. Org. Lett. 2015, 17, 5504.

[61] Tobisu, M.; Nakamura, R.; Kita, Y.; Chatani, N. J. Am. Chem. Soc. 2009, 131, 3174.

[62] Hooper, J. F.; Young, R. D.; Weller, A. S.; Willis, M. C. Chem.-Eur. J. 2013, 19, 3125.

[63] Vandekerkhove, A.; Claes, L.; De Schouwer, F.; Van Goethem, C.; Vankelecom, I. F. J.; Lagrain, B.; De Vos, D. E. ACS Sustainable Chem. Eng. 2018, 6, 9218.

[64] Chatani, N.; Tatamidani, H.; Ie, Y.; Kakiuchi, F.; Murai, S. J. Am. Chem. Soc. 2001, 123, 4849 .

[65] Tatamidani, H.; Yokota, K.; Kakiuchi, F.; Chatani, N. J. Org. Chem. 2004, 69, 5615

[66] Mazziotta, A.; Madsen, R. Eur. J. Org. Chem. 2017, 2017, 5417.

[67] Nishibayashi, Y.; Shinoda, A.; Miyake, Y.; Matsuzawa, H.; Sato, M. Angew. Chem., Int. Ed. 2006, 45, 4835.

[68] Dai, X.-J.; Li, C.-J. J. Am. Chem. Soc. 2016, 138, 5433

[69] Narayanam, J. M. R.; Tucker, J. W.; Stephenson, C. R. J. J. Am. Chem. Soc. 2009, 131, 8756.

[70] You, T.; Wang, Z.; Chen, J.; Xia, Y. J. Org. Chem. 2017, 82, 1340.

[71] (a) Dang, H.; Cox, N.; Lalic, G. Angew. Chem., Int. Ed. 2014, 53, 752.

(b) Lei, L.; Li, C.; Mo, D. Chin. J. Org. Chem. 2019, 39, 2989 (in Chinese). (雷禄, 李承璟, 莫冬亮, 有机化学, 2019, 39, 2989.)

[72] Font, M.; Quibell, J. M.; Perry, G. J. P.; Larrosa, I. Chem. Commun. 2017, 53, 5584.

[73] Gooßen, L. J.; Thiel, W. R.; Rodríguez, N.; Linder, C.; Melzer, B. Adv. Synth. Catal. 2007, 349, 2241.

[74] Goossen, L. J.; Manjolinho, F.; Khan, B. A.; Rodríguez, N. J. Org. Chem. 2009, 74, 2620.

[75] Cahiez, G.; Moyeux, A.; Gager, O.; Poizat, M. Adv. Synth. Catal. 2013, 355, 790 .

[76] Li, Z.; Fu, Z.; Zhang, H.; Long, J.; Songa, Y.; Cai, H. New J. Chem. 2016, 40, 3014

[77] Fichez, J.; Prestat, G.; Busca, P. Org. Lett. 2018, $20,2724$.

[78] Nakazawa, H.; Kamata, K.; Itazaki, M. Chem. Commun. 2005, 36,
4004.

[79] Yang, Z.; Kumar, R. K.; Liao, P.; Liu, Z.; Li, X.; Bi, X. Chem. Commun. 2016, 52, 5936.

[80] Iwai, T.; Fujihara, T.; Tsuji, Y. Chem. Commun. 2008, 46, 6215.

[81] Huang, J.-L.; Dai, X.-J.; Li, C.-J. Eur. J. Org. Chem. 2013, 2013, 6496.

[82] Yang, S.; Tang, W.; Yang, Z.; Xu, J. ACS Catal. 2018, 8, 9320.

[83] Nguyen, J. D.; Matsuura, B. S.; Stephenson, C. R. J. J. Am. Chem. Soc. 2014, 136, 1218.

[84] Lu, P.; Sanchez, C.; Cornella, J.; Larrosa, I. Org. Lett. 2009, 11, 5710 .

[85] Grainger, R.; Nikmal, A.; Cornella, J.; Larrosa, I. Org. Biomol. Chem. 2012, 10, 3172 .

[86] Seo, S.; Taylor, J. B.; Greaney, M. F. Chem. Commun. 2012, 48 , 8270.

[87] Liao, R.-Z.; Chen, S.-L.; Siegbahn, P. E. M. ACS Catal. 2015, 5, 7350.

[88] Ren, Y.-L.; Tian, M.; Tian, X.-Z.; Wang, Q.; Shang, H.; Wang, J.; Zhang, Z. C. Catal. Commun. 2014, 52, 36.

[89] (a) Zhang, L.; Koreeda, M. J. Am. Chem. Soc. 2004, 126, 13190. (b) Jordan, P. A.; Miller, S. J. Angew. Chem., Int. Ed. 2012, 51, 2907.

[90] García, N.; García-García, P.; Fernández-Rodríguez, M. A.; Rubio, R.; Pedrosa, M. R.; Arnáiz, F. J.; Sanz, R. Adv. Synth. Catal. 2012, $354,321$.

[91] Sousa, S. C. A.; Fernandes, T. A.; Fernandes, A. C. Eur. J. Org. Chem. 2016, 2016, 3109 .

[92] (a) Dupuy, S.; Lazreg, F.; Slawin, A. M. Z.; Cazin, C. S. J.; Nolan, S. P. Chem. Commun. 2011, 47, 5455. (b) Dupuy, S.; Nolan, S. P. Chem.-Eur. J. 2013, 19, 14034.

[93] Yasuda, M.; Onishi, Y.; Ueba, M.; Miyai, T.; Baba, A. J. Org. Chem. 2001, 66, 7741.

[94] Miura, K.; Tomita, M.; Yamada, Y.; Hosomi, A. J. Org. Chem. 2007, 72, 787.

[95] Bauer, J. O.; Chakraborty, S.; Milstein, D. ACS Catal. 2017, 7, 4462.

[96] Zou, Y.-Q.; Chakraborty, S.; Nerush, A.; Oren, D.; Diskin-Posner, Y.; Ben-David, Y.; Milstein, D. ACS Catal. 2018, 8, 8014.

[97] Moseley, J. D.; Gilday, J. P. Tetrahedron 2006, 62, 4690.

[98] Diéguez, H. R.; López, A.; Domingo, V.; Arteaga, J. F.; Dobado, J. A.; Herrador, M. M.; Quílez del Moral, J. F.; Barrero, A. F. J. Am. Chem. Soc. 2010, 132, 254

[99] Meyer, V. J.; Niggemann, M. Chem.-Eur. J. 2012, 18, 4687.

[100] Li, P.; Ma, N.; Wang, Z.; Dai, Q.; Hu, C. J. Org. Chem. 2018, 83, 8233.

[101] Gevorgyan, V.; Rubin, M.; Benson, S.; Liu, J.-X.; Yamamoto, Y. J. Org. Chem. 2000, 65, 6179.

[102] Chandrasekhar, S.; Reddy, C. R.; Babu, B. N. J. Org. Chem. 2002, 67, 9080.

[103] Milne, J. E.; Storz, T.; Colyer, J. T.; Thiel, O. R.; Seran, M. D.; Larsen, R. D.; Murry, J. A. J. Org. Chem. 2011, 76, 9519.

[104] Wang, Y. P.; Liu, Y. H.; Ruan, R. S.; Wan, Y. Q.; Zhang, J. S.; Peng, H. Acta Chim. Sinica 2012, 70, 114 (in Chinese). (王允戋，刘玉环，阮榕生，万益琴，张锦胜，彭红，化学学报, 2012, 70, 114.)

[105] Griffin, J. D.; Zeller, M. A.; Nicewicz, D. A. J. Am. Chem. Soc. 2015, 137, 11340

[106] Yang, W.; Gao, L.; Lu, J.; Song, Z. Chem. Commun. 2018, 54 , 4834.

[107] Liu, D.; Sun, J.; Simmons, B. A.; Singh, S. ACS Sustainable Chem. Eng. 2018, 6, 7232.

[108] Zhao, X.; Zheng, X.; Yang, B.; Sheng, J.; Lu, K. Org. Biomol. Chem. 2018, 16, 1200.

[109] Fukuyama, T.; Fujita, Y.; Miyoshi, H.; Ryu, I.; Kao, S.-C.; Wu, Y.-K. Chem. Commun. 2018, 54, 5582.

(Zhao, C.) 